\title{
Physical Activity Monitoring in Patients with Neurological Disorders: A Review of Novel Body-Worn Devices
}

\author{
Oonagh M. Giggins ${ }^{a, b}$ leuan Clay ${ }^{c}$ Lorcan Walsh ${ }^{b}$ \\ a Insight Centre for Data Analytics, University College Dublin, O'Brien Centre for Science, \\ Science Centre East, Belfield, Dublin, Ireland; b Novartis Business Services, Elm Park, Dublin, \\ Ireland; ' Novartis Institutes for Biomedical Research, Novartis Campus, Basel, Switzerland
}

\section{Keywords}

Wearable sensor - Activity monitor - Mobility · Motor activity · Physical activity

\section{Abstract}

Aim: The aim was to conduct a systematic review to examine the literature reporting the validity and reliability of wearable physical activity monitoring in individuals with neurological disorders. Method: A systematic search of the literature was performed using a specific search strategy in PubMed and CINAHL. A search constraint of articles published in English, including human participants, published between January 2008 and March 2017 was applied. Peerreviewed studies which enrolled adult participants with any neurological disorder were included. For the studies which sought to explore the validity of activity monitors, the outcomes measured using the monitor were compared to a criterion measure of physical activity. The studies' methodological quality was assessed using an adapted version of the Quality Assessment of Diagnostic Accuracy Studies (QUADAS) framework. Data extracted from each study included the following: characteristics of the study participants, study setting, devices used, study protocol/methods, outcomes measured, and the validity/reliability of measurement produced. Results: Twenty-three studies examining the validity and reliability of 16 different monitors were included. The identified studies comprised participants with a range of different disorders of neurological origin. The available evidence suggests that biaxial or triaxial accelerometer devices positioned around the ankle produce the most accurate step count measurements in patients with neurological disorders. The findings regarding the reliability and validity of activity counts and energy expenditure are largely inconclusive in this population. Discussion: Ankle-worn biaxial or triaxial accelerometer-type devices provide the most accurate measurement of physical activity. However, further work is required in this field be- 
Giggins et al.: Physical Activity Monitoring in Patients with Neurological Disorders: A Review of Novel Body-Worn Devices

fore wearable activity monitoring can be more widely implemented clinically. Standardised activity monitoring protocols are required for implementing these devices in clinical trials and clinical practice, and consensus is required as to the reporting and interpretation of derived variables.

(C) 2017 The Author(s)

Published by S. Karger AG, Basel

\section{Introduction}

Regular physical activity is essential for health and well-being and has been shown to contribute to the prevention of many illnesses [1-4], as well as being a vital element in the treatment, rehabilitation, and management of many conditions [5-7]. Physical activity is defined as "any bodily movement produced by skeletal muscles that results in the expenditure of energy" [8] and can be quantified either in terms of mobility (e.g., number of steps) or energy expenditure. Mobility is central to our quality of life. Mobility limitation is often the first noticeable sign of declining function and is associated with reduced independence and disability [9], longer hospital stays [10], nursing home placement [11], and mortality [9]. Measuring physical activity, and particularly mobility, allows clinicians to understand a patient's functional ability and to decide upon treatment or prognosis. Physical activity and mobility have traditionally been assessed by questionnaires, surveys, and activity diaries. These assessment methods are easy to administer to large groups and can be performed at low cost [12]. However, the subjectivity of these tests means that they have limitations [13]. They may lack the precision needed to detect small changes in physical activity and mobility, and the granularity to characterise daily fluctuations in disease severity. They may also be vulnerable to error caused by manual input either by the patient or the investigator/clinician.

The proliferation of unobtrusive, wearable devices has made it easier to capture objective data relevant to physical activity and mobility. Wearable monitors, which are used to estimate physical activity and mobility, can be broadly classified into one of three types: pedometers, accelerometers, and multisensor systems. Pedometers (e.g., Yamax Digi-Walker) estimate the number of steps taken through mechanical (using a spring-mounted level arm) or digital measurements in only the vertical plane [14]. Accelerometers (e.g., RT3 accelerometer) detect acceleration in one (uniaxial), two (biaxial), or three (triaxial) directions and can determine the quantity and intensity of movement [14]. Multisensor systems (e.g., SenseWear Armband) combine accelerometry with other sensors measuring data such as heart rate, galvanic skin response, or temperature, yielding more data to base physical activity estimations upon.

Using body-worn activity monitors may provide a more robust, objective, and detailed method of assessing physical activity and mobility than traditional assessment methods such as questionnaires and standardised tests. The objective data provided may support the clinical decision-making process, assisting clinicians to better visualise changes in motor function. Furthermore, utilising wearable activity monitors permits continuous patient monitoring by allowing data collection in the patient's own home [15]. These out-of-clinic data may provide a more accurate representation of the patient's ability, as some patients perform better in the clinical environment when under the observation of a clinician [16], while others perform better in the familiar environment of their own home. This approach also has the potential to reduce the burden on both the patient and the clinical site by decreasing the utilisation of valuable resources.

Recent years have witnessed a significant growth in the array of activity monitors with considerable clinical potential. However, despite their potential, they have not yet been widely employed in clinical practice. This may be due to the fact that there is relatively little 
Giggins et al.: Physical Activity Monitoring in Patients with Neurological Disorders: A Review of Novel Body-Worn Devices

evidence regarding the accuracy of these activity monitors, and the lack of regulatory approval for many devices. Clinicians may also have concerns related to data privacy and the security of the data produced by these devices. Other cited barriers to their clinical utilisation include the lack of understanding of how to summarise the data gathered to produce meaningful outcome measures that can inform the clinical decision-making process, and also the lack of standards for implementing these devices clinically [17].

A number of reviews have been published which have examined the validity and reliability of using wearable sensors to measure physical activity in chronic lung disease and in stroke patients $[14,18,19]$. The studies included in these reviews were highly heterogeneous in terms of the type of activity monitor used, the activity monitor outcome reported, and the methods used for data collection and analysis. Nonetheless, the evidence presented suggests that multiaxial accelerometer or multisensor devices appear to produce the most valid and reliable data about physical activity in chronic disease populations $[14,18,19]$. A recent systematic review concluded that remote physical activity monitoring is feasible in individuals with neurological diseases, including those with moderate-to-severe disability [20]. Another recent review which evaluated a range of wearable and non-wearable devices for objectively measuring a range of motor symptoms in Parkinson disease (PD) highlighted that while a number of devices can be recommended, further clinimetric testing and clinical validation are required [21]. As yet, no review has broadly summarised the evidence regarding the validity and reliability of wearable activity monitoring in patients with neurological conditions for clinical use. The validity and reliability of activity monitoring in other populations may not translate easily to individuals with neurological diseases, as activity monitoring in individuals with neurological diseases may be complicated by a wide range of neurological impairments such as gait abnormalities [22], weakness [23], spasticity [24], or tremor [25]. For example, it has been demonstrated that gait parameters such as speed and distance can be accurately estimated using a triaxial accelerometer device in healthy adults [26], but the accuracy is not as high in individuals with PD while using the same device [27]. Therefore it is important to explore the validity and reliability of activity monitors in this population before these monitors can be widely implemented in clinical trials and practice.

The aim was to conduct a systematic review to examine the literature reporting on the validity and reliability of activity monitoring in individuals with neurological disorders. This review sought to explore the range of activity monitors that have been evaluated in clinical research studies and to explore the outcome measures of physical activity produced by these monitors. The focus of this review was on the clinical application of activity monitors and was not concerned with studies reporting early developments or validations of algorithms for activity monitoring devices.

\section{Materials and Methods}

This review was conducted and is reported according to the Preferred Reporting Items for Systematic Reviews and Meta-Analyses (PRISMA) guidelines [28].

\section{Data Sources}

The PubMed and CINAHL electronic databases were searched to retrieve relevant articles. These databases were chosen based on the method used in previous literature reviews published in the field $[14,19,29]$. Pilot searches conducted in other electronic databases did not yield applicable results. A search constraint of articles published in the English language, including human participants, between January 2008 and March 2017 was applied. Due to 
Giggins et al.: Physical Activity Monitoring in Patients with Neurological Disorders: A Review of Novel Body-Worn Devices

Table 1. Study inclusion/exclusion criteria

\begin{tabular}{lll}
\hline & Inclusion & Exclusion \\
\hline Study type & $\begin{array}{l}\text { Peer-reviewed original papers that evaluated } \\
\text { the validity and/or reliability of a wearable } \\
\text { activity monitor }\end{array}$ & $\begin{array}{l}\text { Review articles } \\
\text { Case reports/intervention studies using an } \\
\text { activity monitor as a component of an } \\
\text { intervention or to measure the impact of an } \\
\text { intervention }\end{array}$ \\
& & $\begin{array}{l}\text { Papers that evaluated the validity of } \\
\text { physical activity classification models/ } \\
\text { algorithms or papers that outlined } \\
\text { algorithm development }\end{array}$ \\
\hline Outcomes measured & $\begin{array}{l}\text { Measurements which quantify the amount/ } \\
\text { level of physical activity/mobility, e.g., } \\
\text { step counts, distance, intensity of physical } \\
\text { activity, walking speed, and energy } \\
\text { expenditure }\end{array}$ & $\begin{array}{l}\text { Measurements of postural control } \\
\text { Posture classification measurements }\end{array}$ \\
\hline $\begin{array}{l}\text { Adult participants with a neurological } \\
\text { condition/disorder, i.e., any disease of the } \\
\text { brain, spine, and the nerves that connect } \\
\text { them }\end{array}$ & $\begin{array}{l}\text { Healthy volunteers, paediatric participants } \\
\text { (<18 years of age), athletic populations }\end{array}$ \\
\hline $\begin{array}{l}\text { Any consumer, research, or medical-grade } \\
\text { wearable sensor used to measure physical } \\
\text { activity }\end{array}$ & $\begin{array}{l}\text { Smartphone applications, ambient sensors } \\
\text { Comparison with criterion measure of } \\
\text { physical activity/mobility }\end{array}$ & No comparator \\
\hline Sensor types & & \\
\hline Comparison & & \\
\hline
\end{tabular}

the rapid development of technology in this field, this time frame was selected so as to limit the activity monitors studied to those which are still commercially available.

\section{Search Strategy}

The search in PubMed for relevant studies was performed using the free-text and MeSH terms outlined in Appendix 1. The search terms used in the PubMed search were modified for the CINAHL database. The citation lists from all the included studies were also searched, and a search of breadcrumb-related articles was also performed. The search strategy used was developed in consultation with a librarian.

\section{Study Selection}

The focus of this review was on an examination of the validity and/or reliability of the range of activity monitors that have been clinically utilised to quantify physical activity and mobility in patients with neurological disorders. Validity and reliability measures are referred to as psychometric properties. Validity refers to how well a test measures what it is purported to measure. Criterion validity was explored in this study, i.e., comparing the activity monitor measurement to a criterion measure of physical activity/mobility. Reliability is the degree to which an assessment tool produces stable and consistent results. The reliability or validity of an assessment tool is indicated by a coefficient, such as the intraclass coefficient or Pearson's 


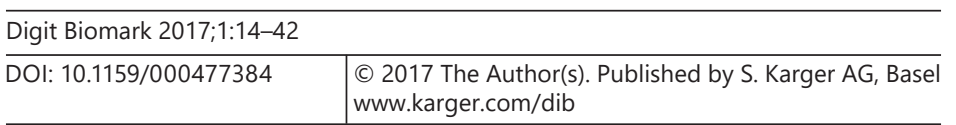

Fig. 1. Flow chart of the review

Giggins et al.: Physical Activity Monitoring in Patients with Neurological Disorders: A Review of Novel Body-Worn Devices process.

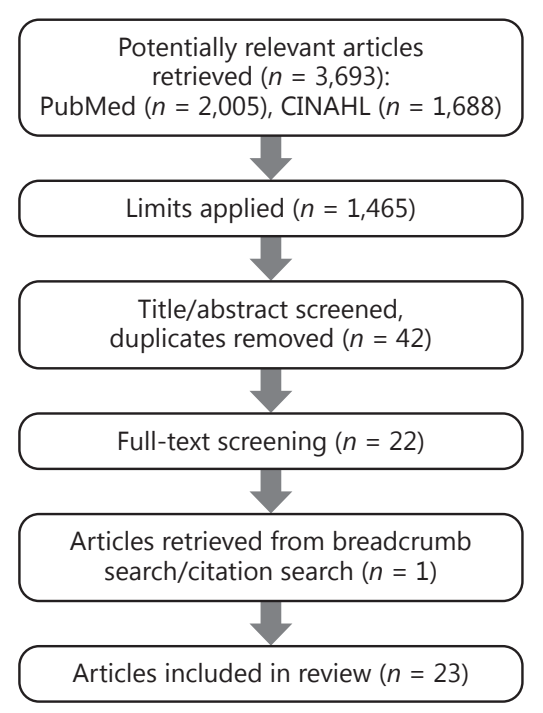

correlation coefficient (where values $\geq 0.90$ generally indicate excellent, $0.75-0.90$ good, $0.50-0.75$ adequate, and $<0.50$ poor results [30]).

Validation and reliability studies of physical activity monitors are highly heterogeneous. Therefore the inclusion/exclusion criteria outlined in Table 1 were applied for the selection of studies included in this review. Studies performed in laboratory, clinical, or free-living (home/community) environments were included. The abstracts and titles of the studies identified from the search process were assessed and screened by the authors in order to decide whether they were suitable for inclusion [19]. The full-text articles of all potentially relevant studies were then retrieved and assessed for inclusion by the authors based on the defined study inclusion/exclusion criteria.

\section{Data Extraction}

Data extracted from each study included the following: characteristics of the study participants, study setting, devices used (make, model, size, weight, and manufacturer), study protocol/methods, outcomes measured, and the validity/reliability of measurement produced. The methodological quality of the validation studies included in this review was assessed using an adapted version of the Quality Assessment of Diagnostic Accuracy Studies (QUADAS) framework [18, 31]. Due to the heterogeneity of the included studies, a metaanalysis was not possible.

\section{Results}

A total of 3,693 potentially relevant articles were retrieved from the literature search performed in the PubMed and CINAHL electronic databases. Figure 1 depicts the study flow throughout the review process. Following a review of the title and abstract and a removal of duplicates, 42 articles remained. The list was subsequently reduced to 22 articles following a review of the full text. One article was retrieved from the citation search/breadcrumb search of the included articles. This yielded a final total of 23 articles for inclusion in this review. 
Giggins et al.: Physical Activity Monitoring in Patients with Neurological Disorders: A Review of Novel Body-Worn Devices

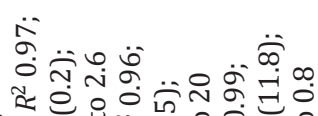

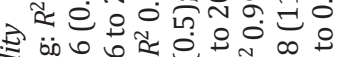

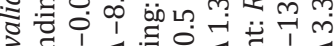
ฮิ 递家

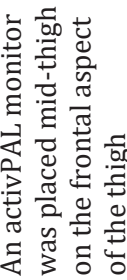

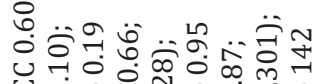

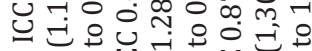
引 ₹ิ

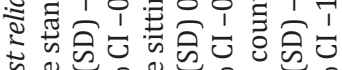

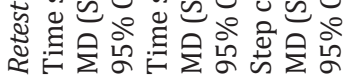

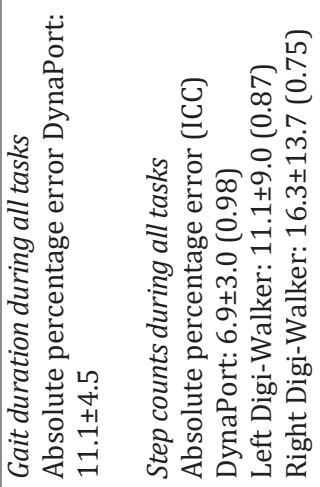

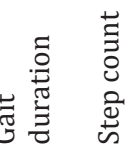
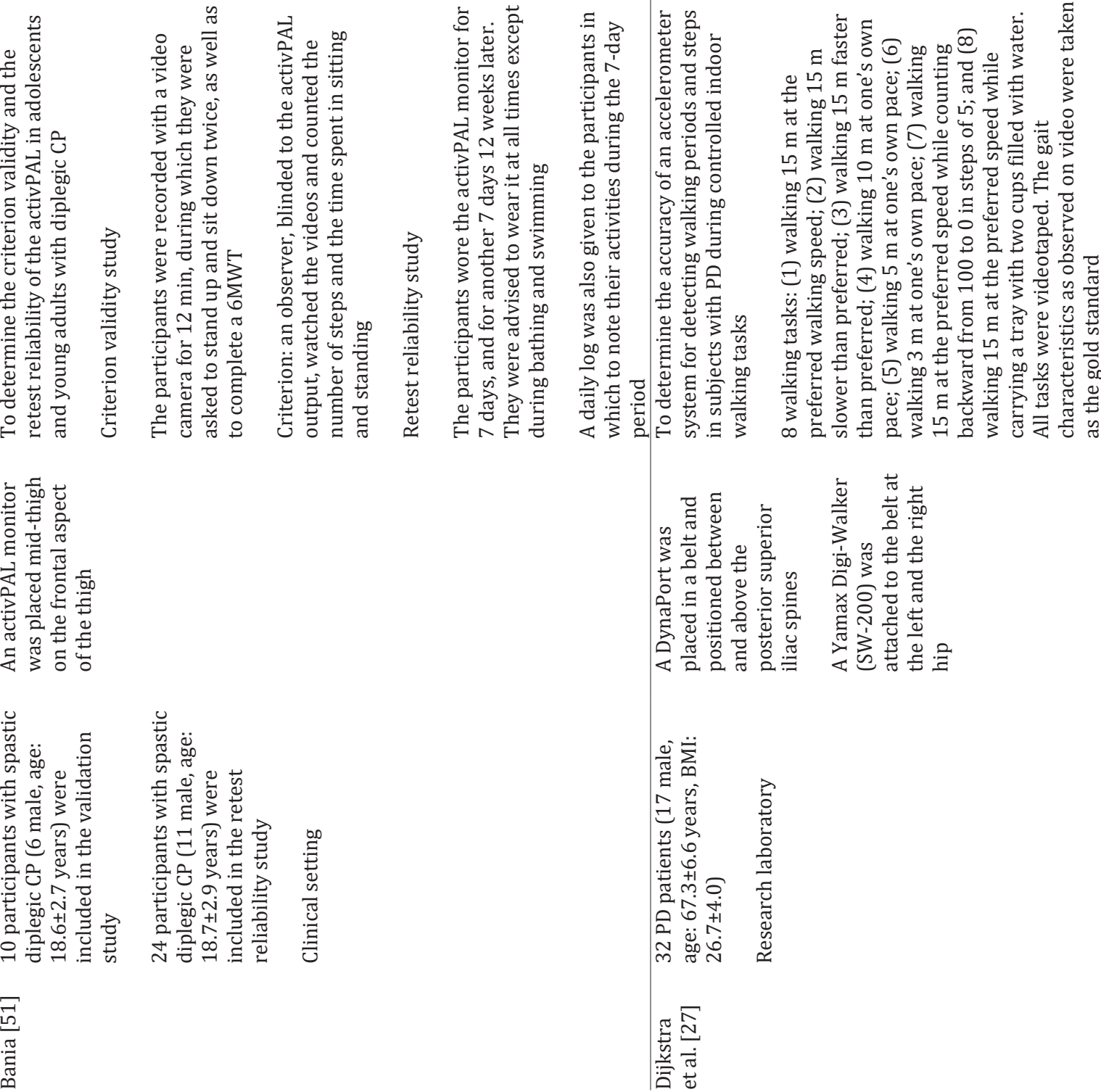
Giggins et al.: Physical Activity Monitoring in Patients with Neurological Disorders: A Review of Novel Body-Worn Devices

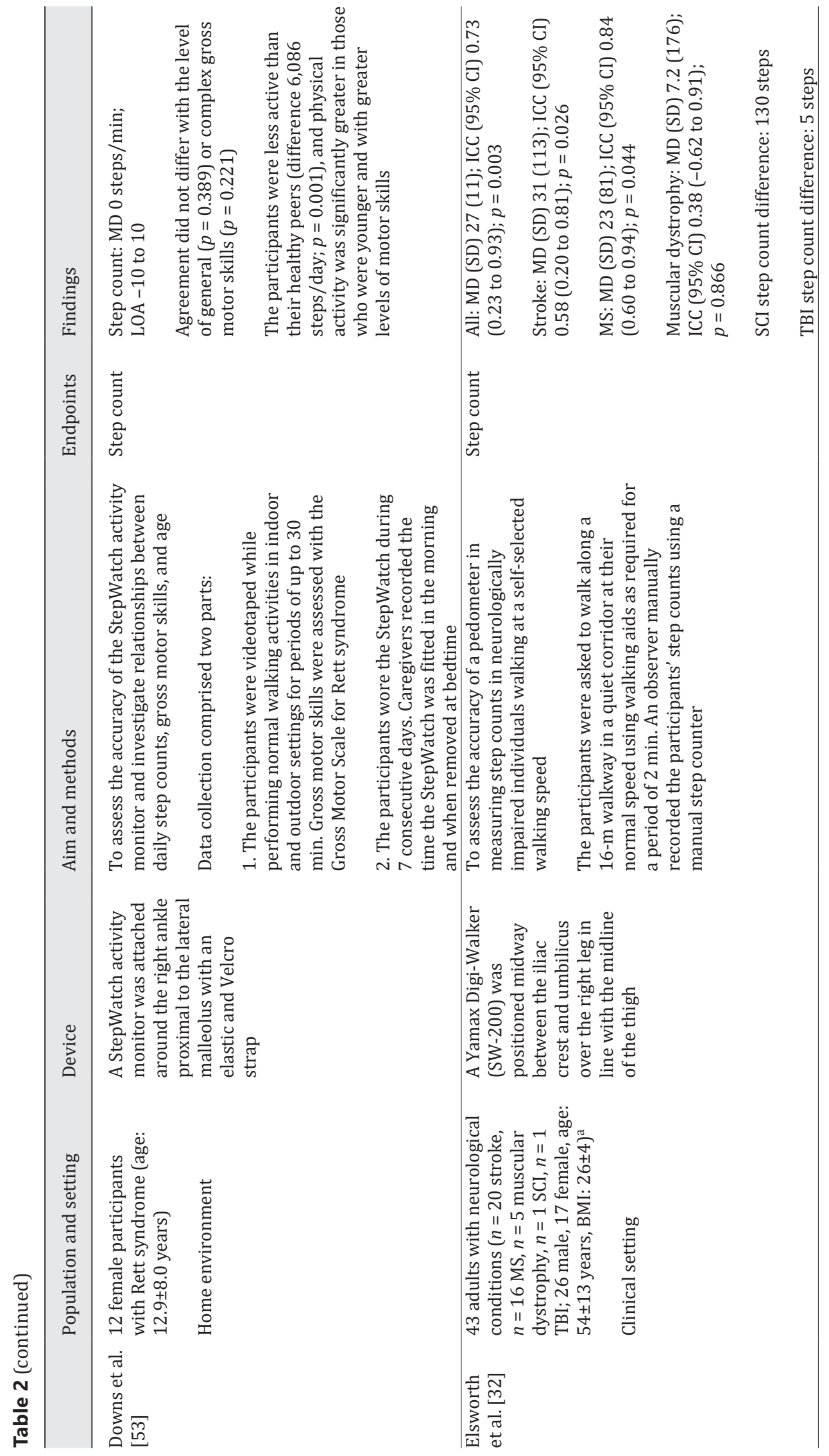


Giggins et al.: Physical Activity Monitoring in Patients with Neurological Disorders: A Review of Novel Body-Worn Devices

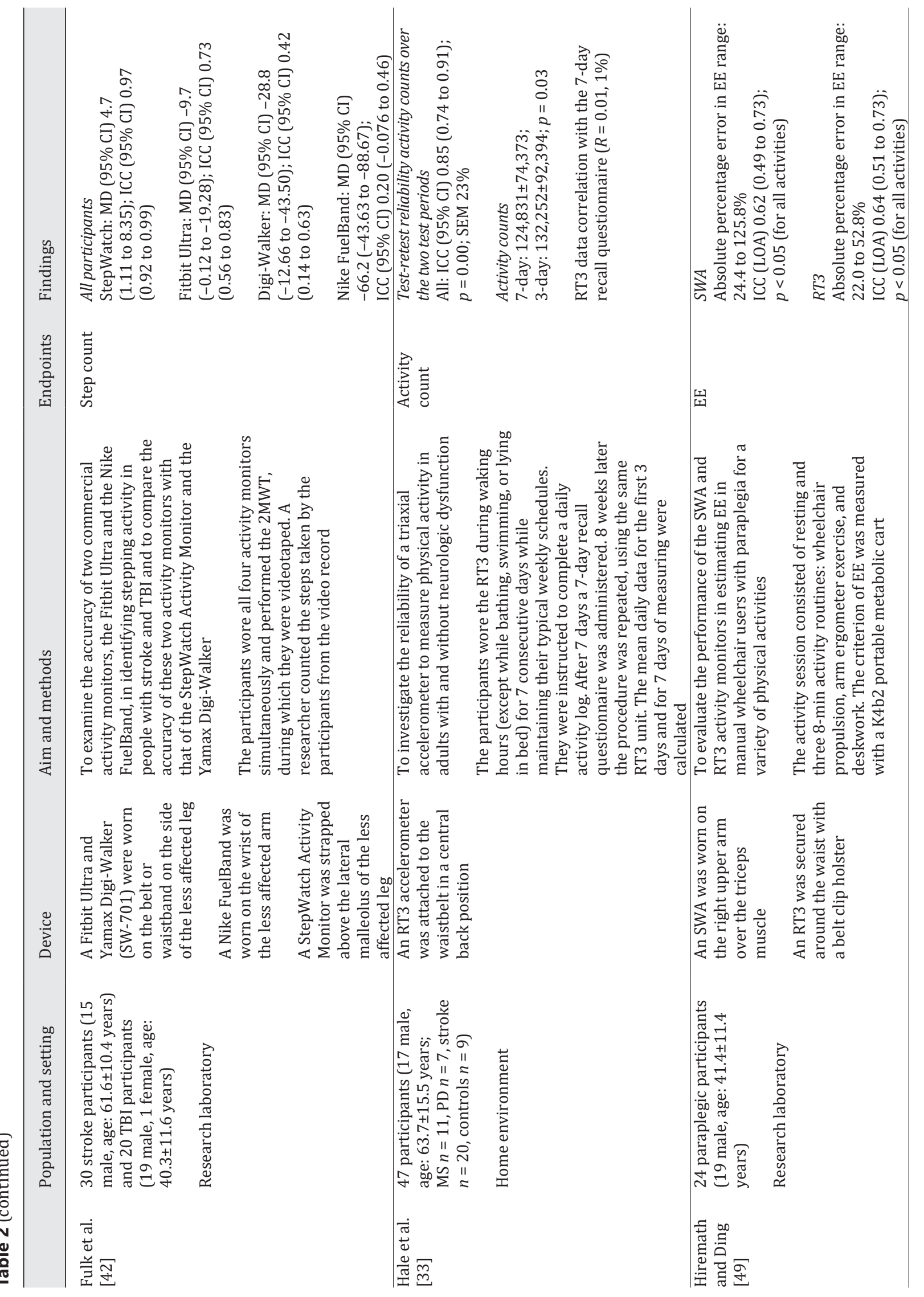


Giggins et al.: Physical Activity Monitoring in Patients with Neurological Disorders: A Review of Novel Body-Worn Devices

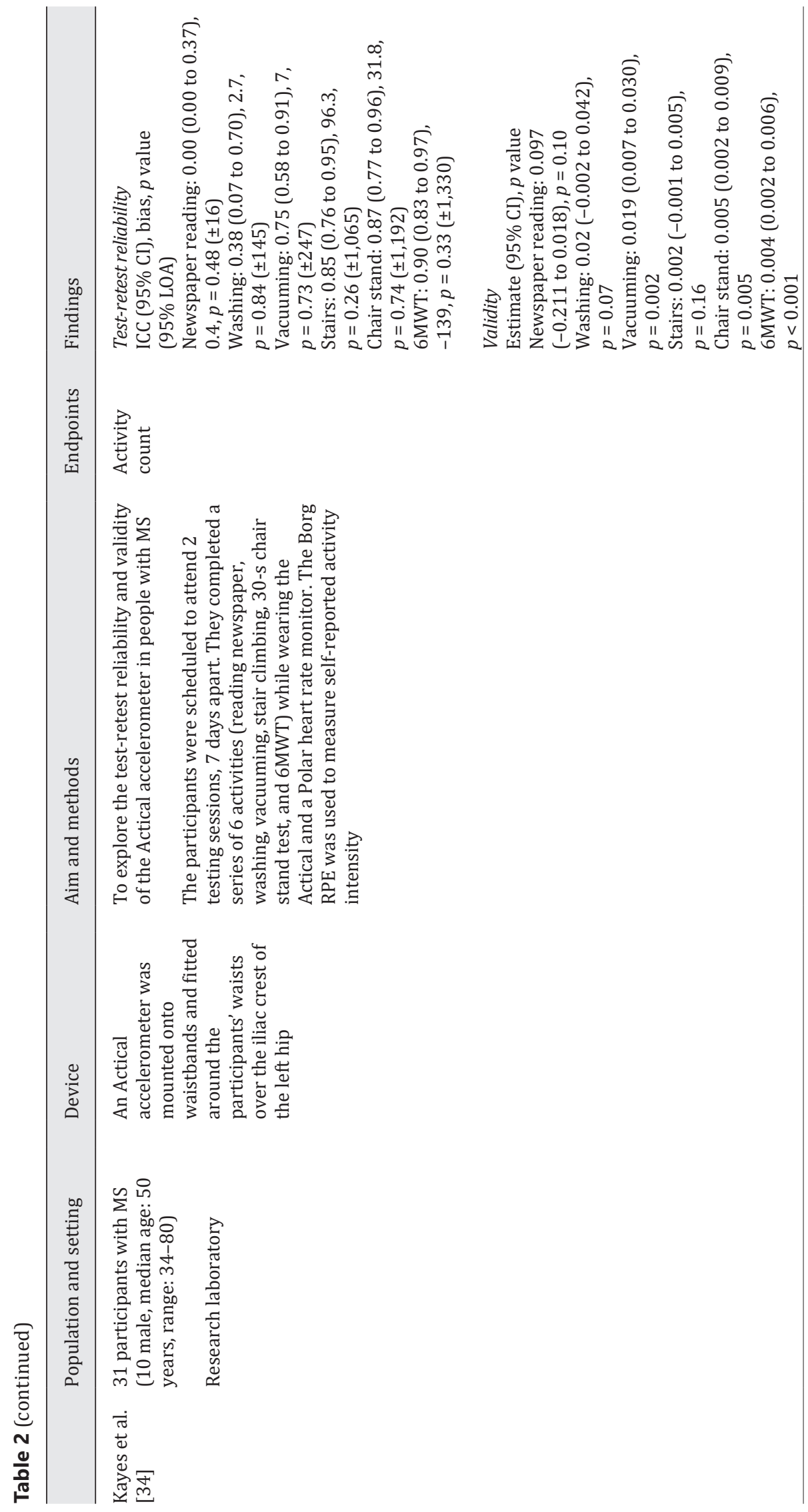


Giggins et al.: Physical Activity Monitoring in Patients with Neurological Disorders: A Review of Novel Body-Worn Devices

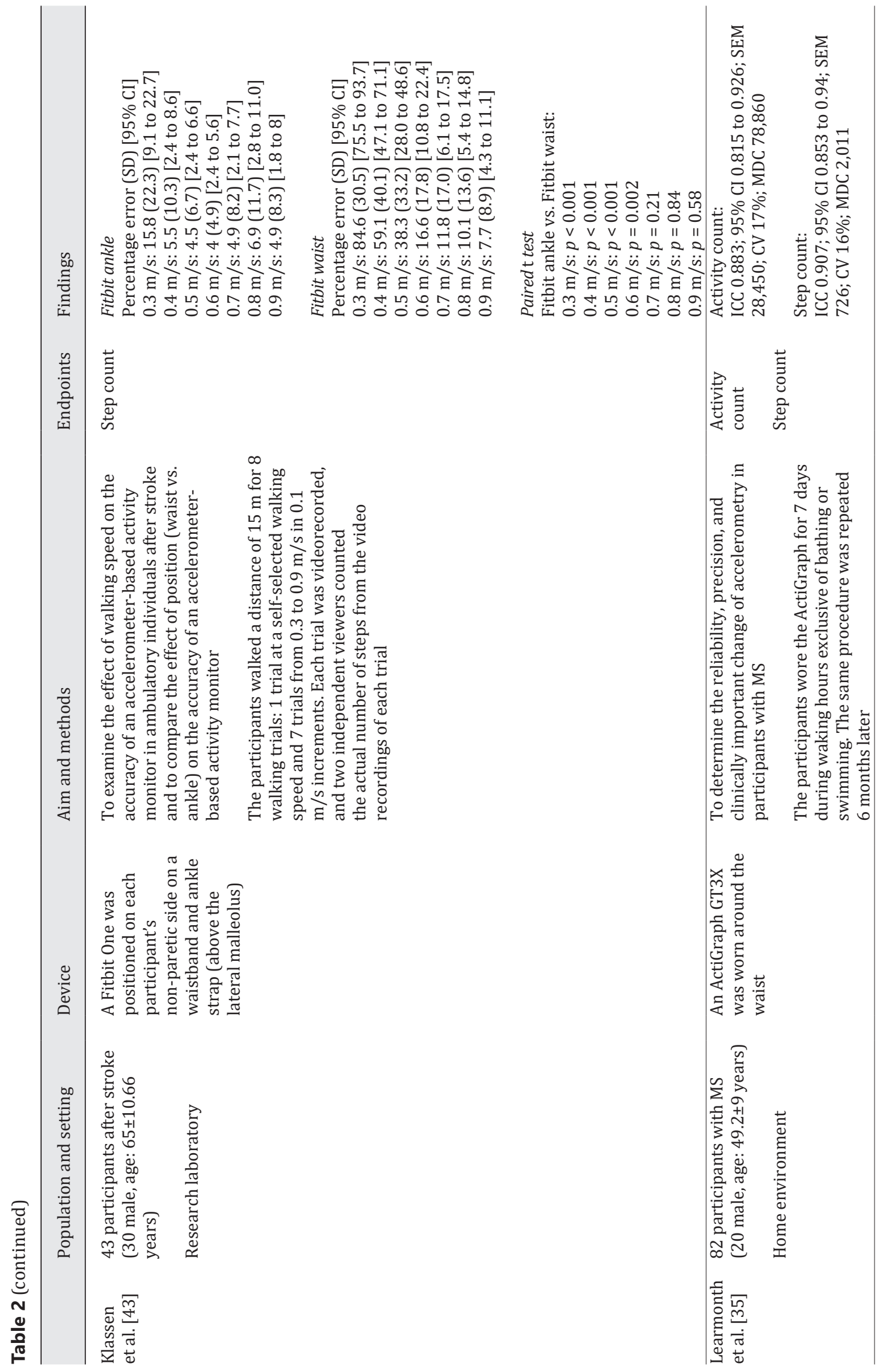


digital

DI๑markers
Digit Biomark 2017;1:14-42

DOI: 10.1159/000477384

Giggins et al.: Physical Activity Monitoring in Patients with Neurological Disorders: A Review of Novel Body-Worn Devices

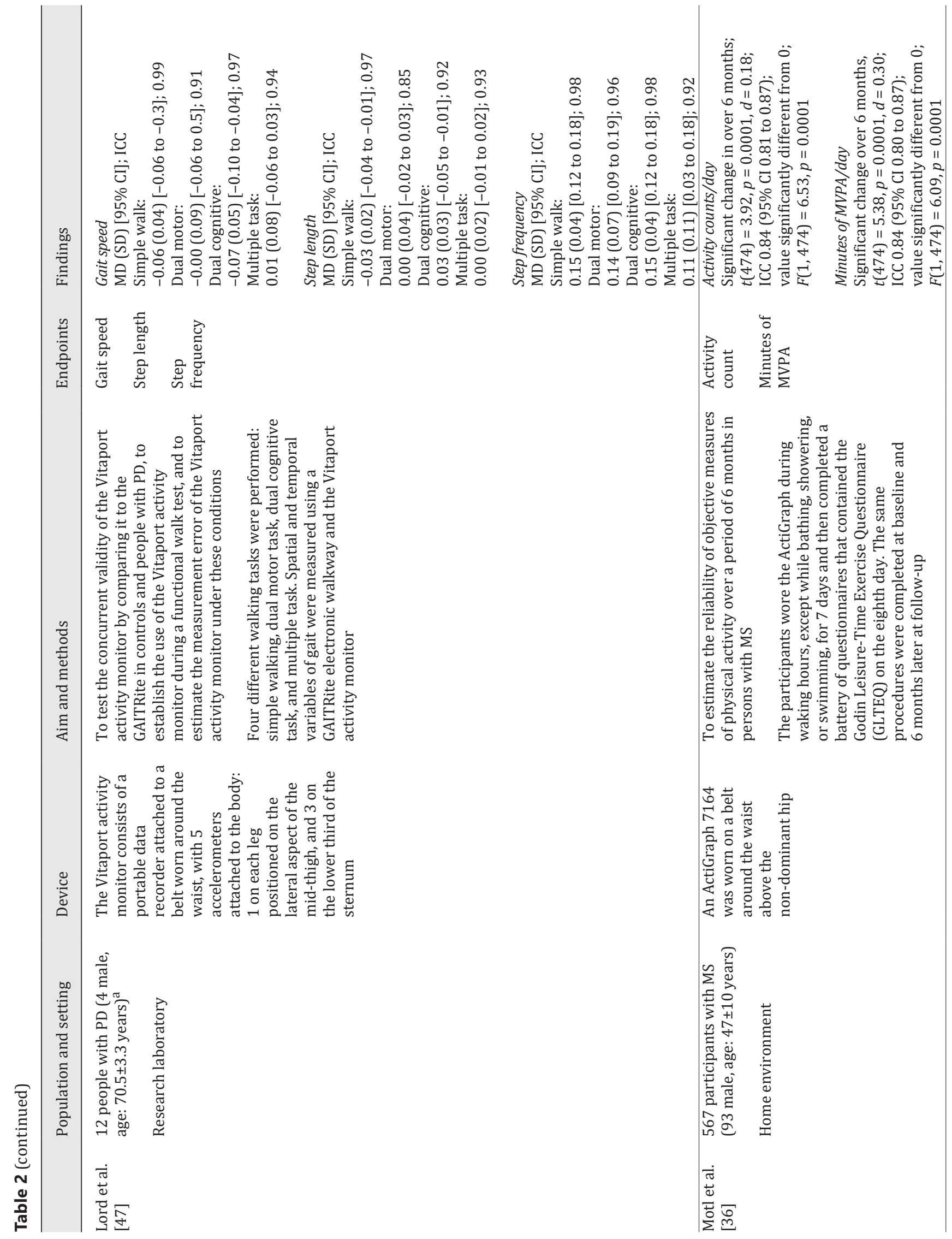


Giggins et al.: Physical Activity Monitoring in Patients with Neurological Disorders: A Review of Novel Body-Worn Devices

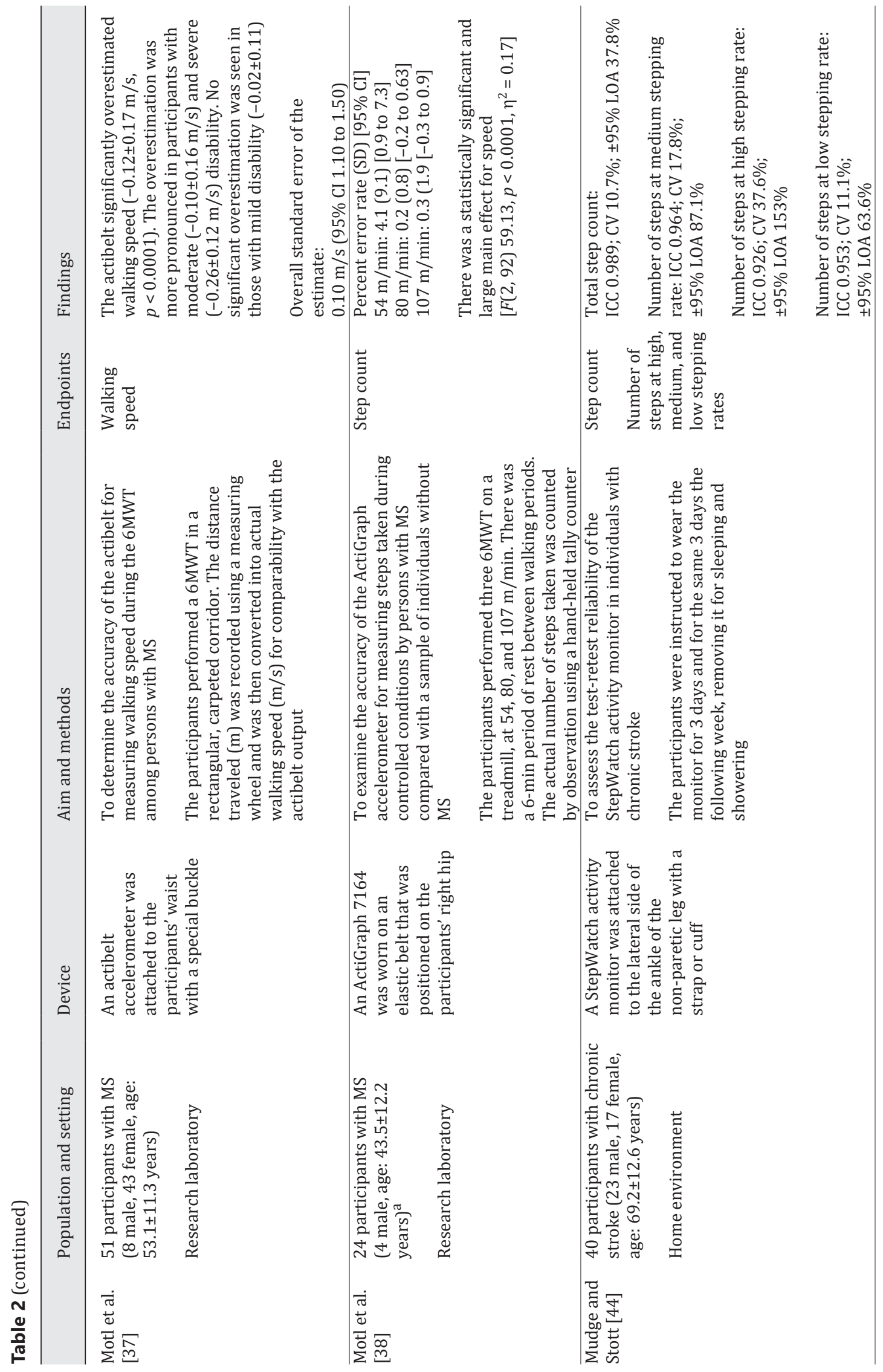


digital

DI๑markers
Digit Biomark 2017;1:14-42

DOI: $10.1159 / 000477384$

c) 2017 The Author(s). Published by S. Karger AG, Basel www.karger.com/dib

Giggins et al.: Physical Activity Monitoring in Patients with Neurological Disorders: A Review of Novel Body-Worn Devices

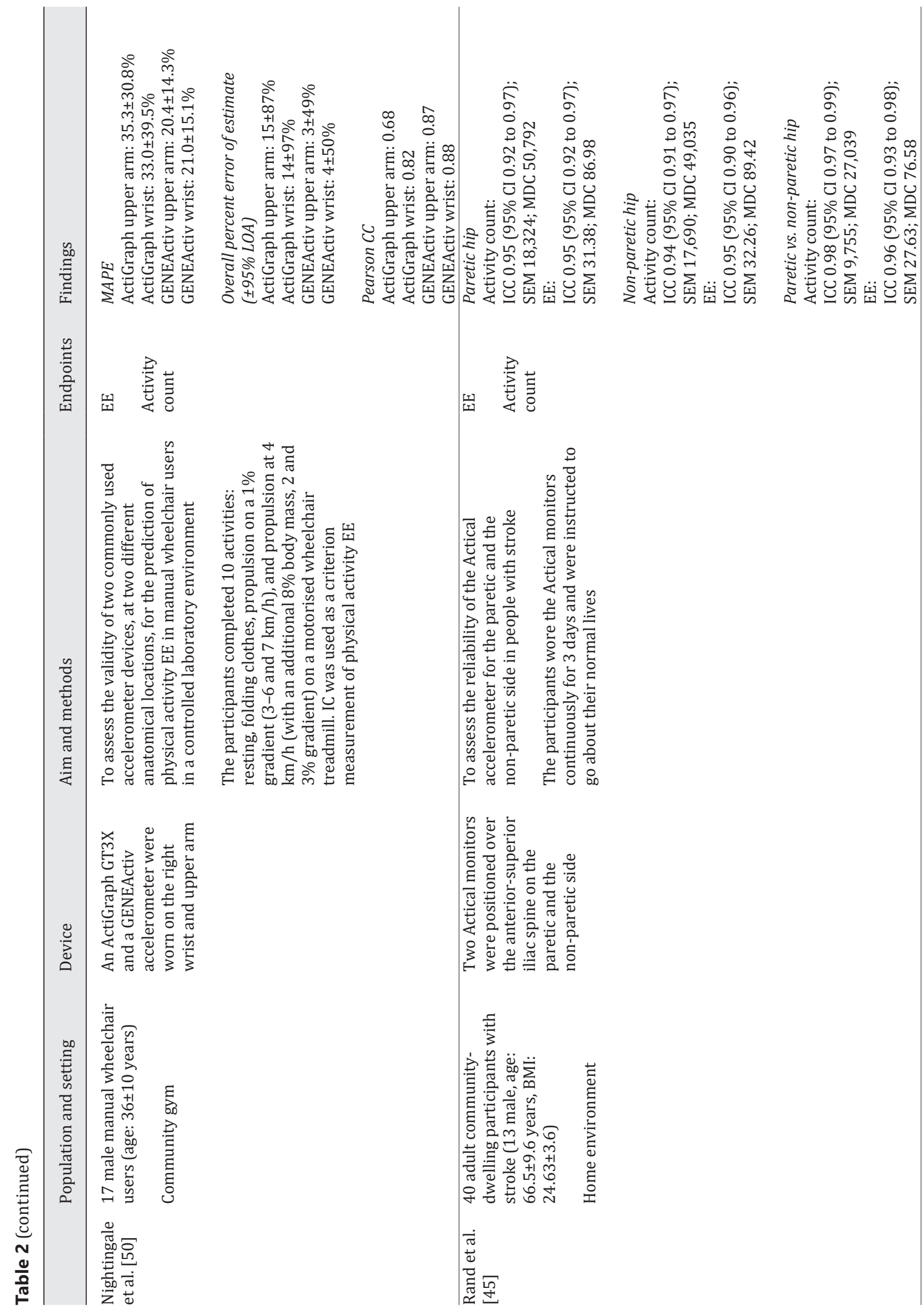


Giggins et al.: Physical Activity Monitoring in Patients with Neurological Disorders: A Review of Novel Body-Worn Devices

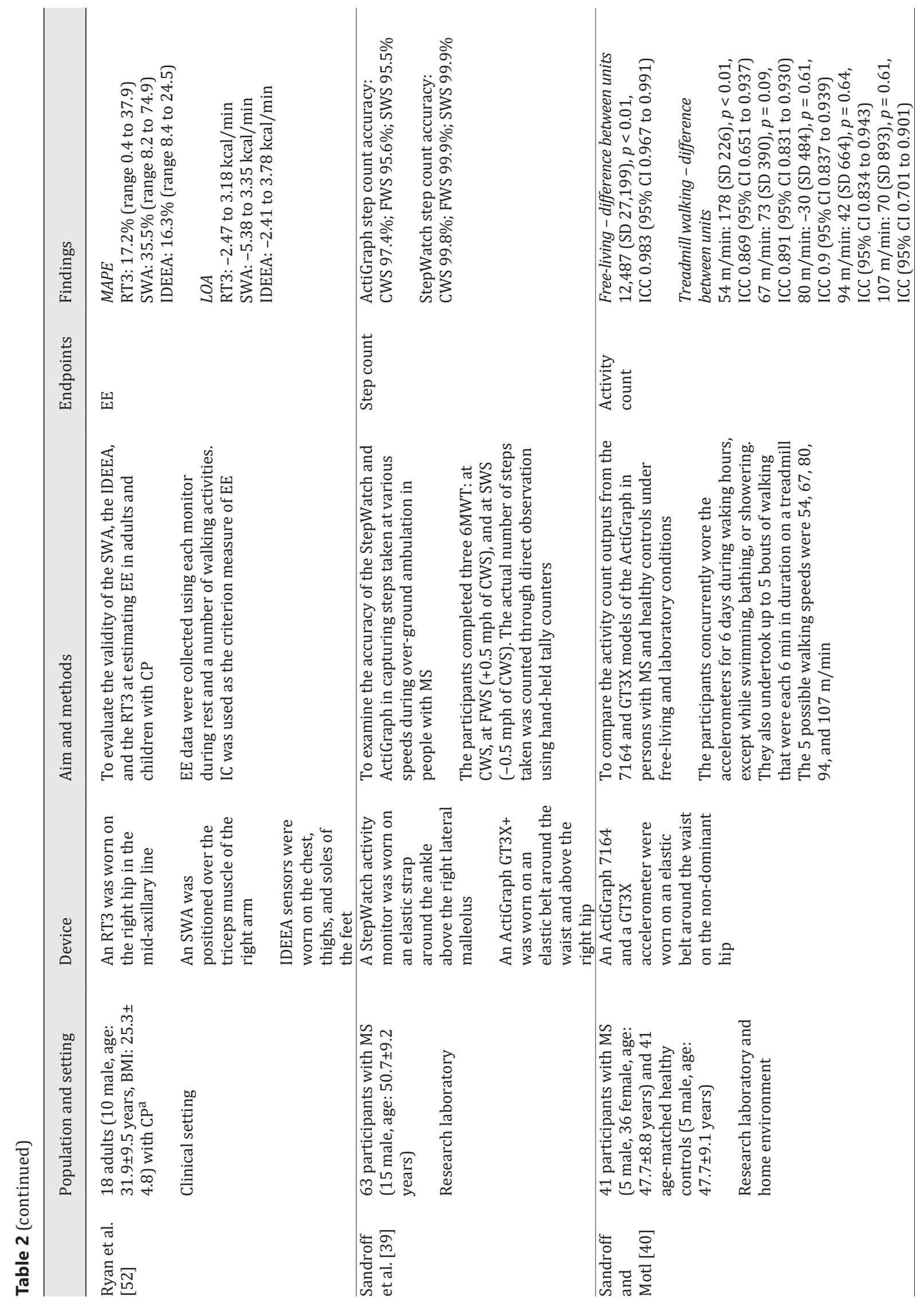


Giggins et al.: Physical Activity Monitoring in Patients with Neurological Disorders: A Review of Novel Body-Worn Devices

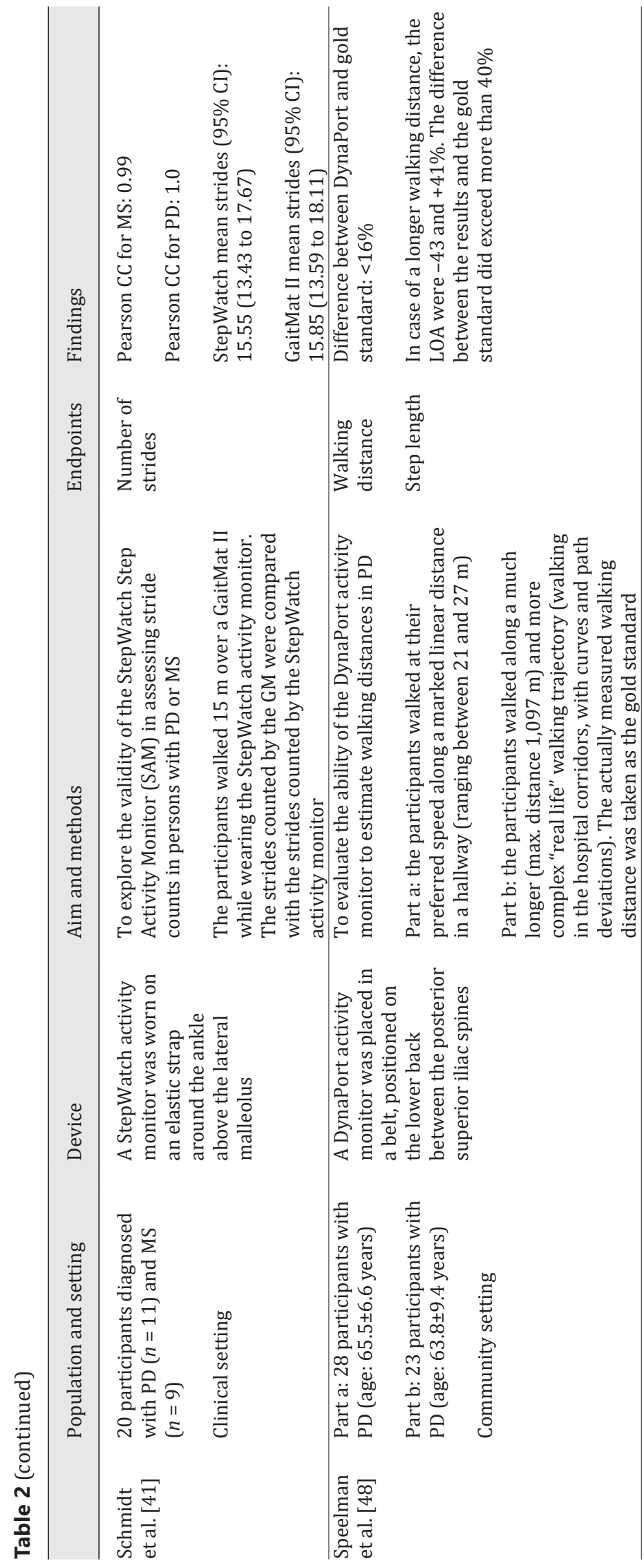


미미미

DI๑markers
Digit Biomark 2017;1:14-42

DOI: $10.1159 / 000477384$

(c) 2017 The Author(s). Published by S. Karger AG, Basel www.karger.com/dib

Giggins et al.: Physical Activity Monitoring in Patients with Neurological Disorders: A Review of Novel Body-Worn Devices

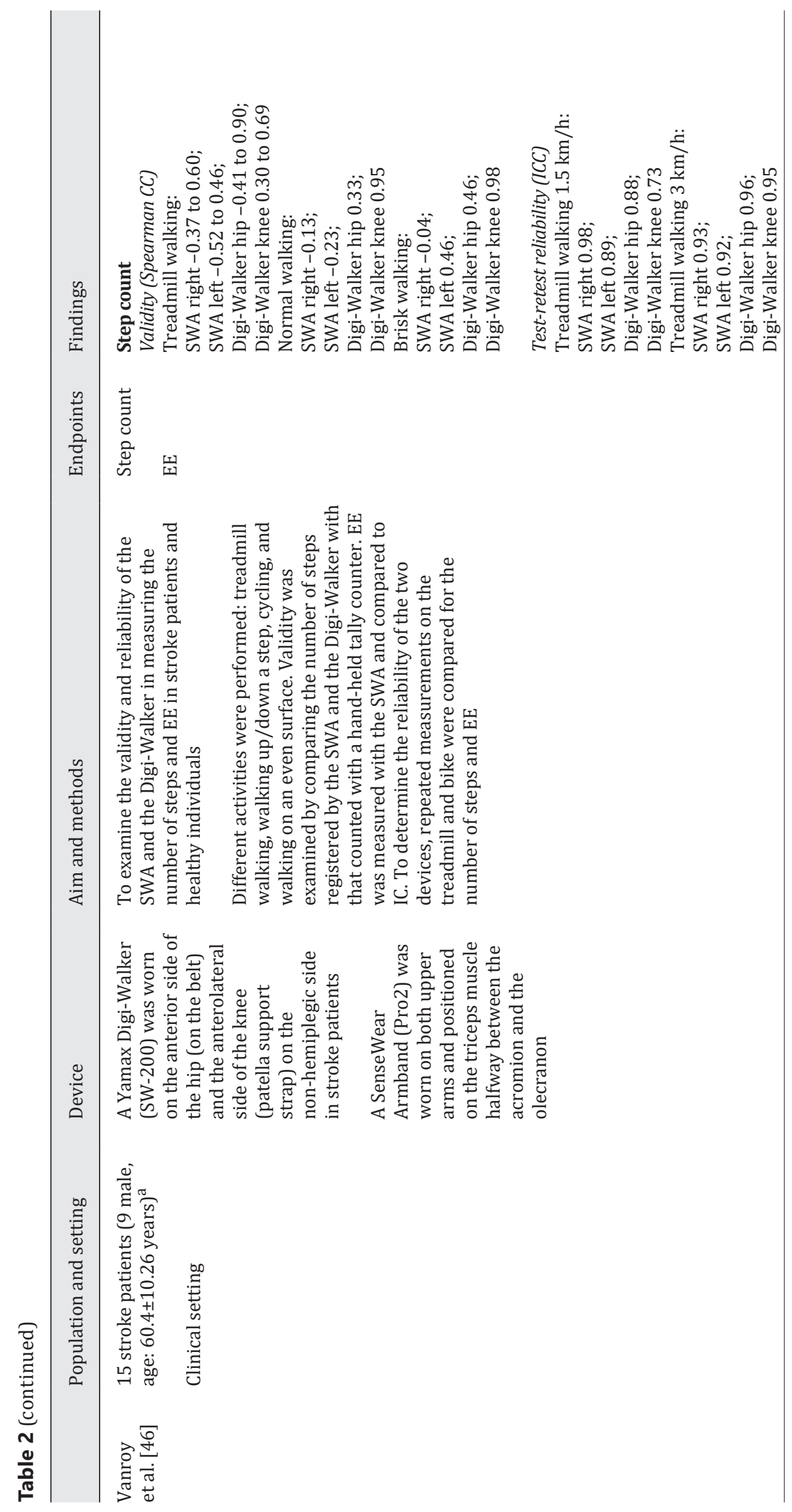


Giggins et al.: Physical Activity Monitoring in Patients with Neurological Disorders: A Review of Novel Body-Worn Devices

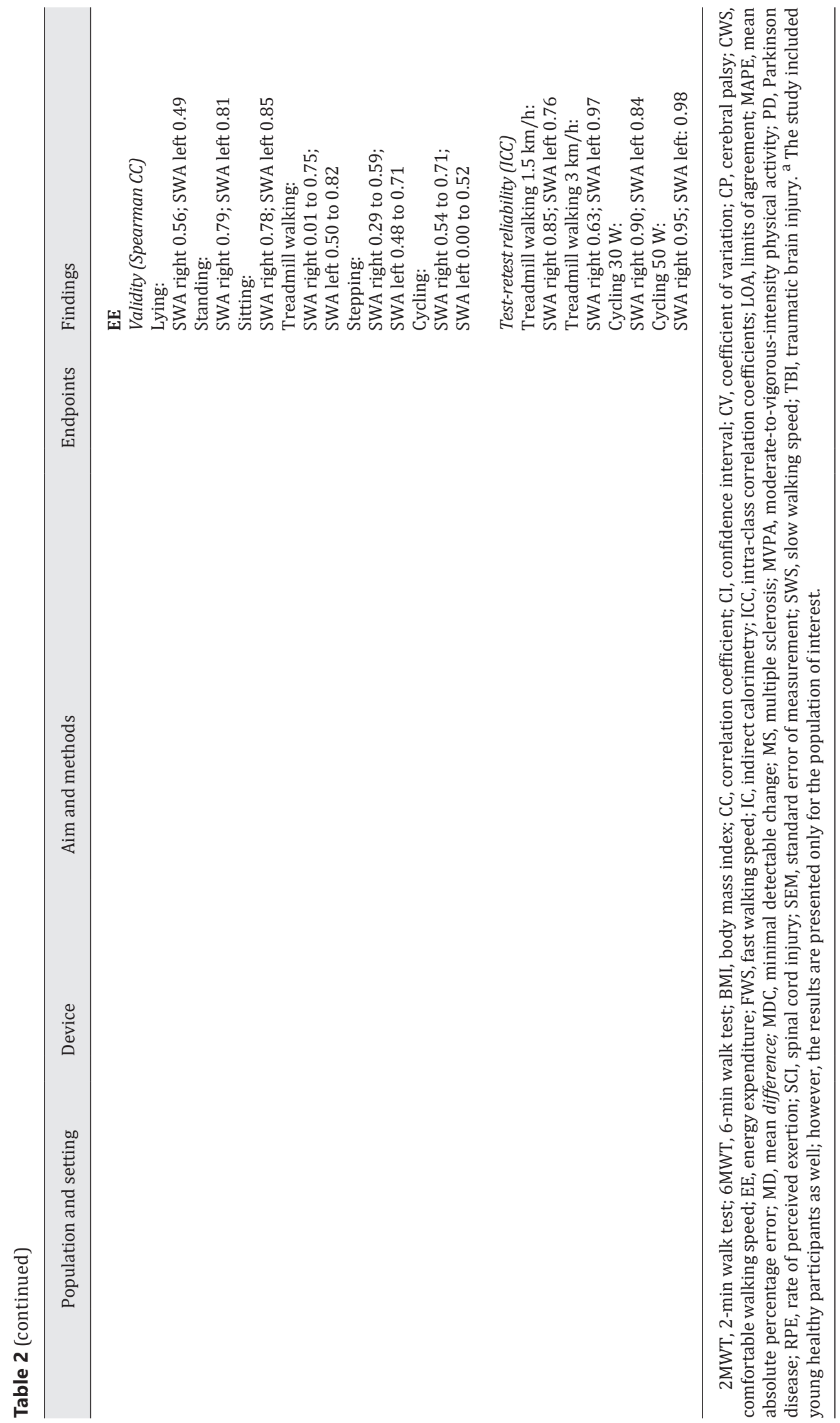


Giggins et al.: Physical Activity Monitoring in Patients with Neurological Disorders: A Review of Novel Body-Worn Devices

A detailed description of each study included in this review is presented in Table 2 . The methodological quality of each validation study is presented in Appendix 2. Overall the methodological quality of the studies examined was high, with each scoring $\geq 7$. Of the assessed studies, 10 included participants with multiple sclerosis [32-41], 7 included participants after stroke [32, 33, 42-46], 4 included participants with PD [27, 33, 47, 48], 3 included participants with a spinal cord injury [32, 49, 50], 2 included participants with cerebral palsy [51, 52], 2 included participants with a traumatic brain injury [32, 42], and participants with Rett syndrome [53] and muscular dystrophy [32] were included in 1 study each. The most frequently used monitors included the StepWatch activity monitor (a biaxial accelerometer) $[39,41,42,44,53]$, the ActiGraph GT3X (a triaxial accelerometer) $[35,39,40,50]$, the SWA (a multisensor device) $[46,49,52]$, and the Digi-Walker pedometer [27, 32, 34, 42]. Table 3 outlines the monitors that were used in the included studies, the outcome measures produced, and the findings reported regarding the validity and reliability of the measurements produced.

\section{Discussion}

This review identified 23 studies examining the validity and reliability of 16 different monitors ( 9 triaxial accelerometer-type monitors, 1 biaxial accelerometer-type monitor, 2 uniaxial accelerometer-type monitors, 3 multisensor devices, and 1 spring-mounted lever arm pedometer-type monitor) in individuals with neurological disorders. The studies included in this review were highly heterogeneous in terms of their study design, the participants included, the activity monitors used, the placement of the monitor on the body, the outcomes measured, and the algorithms used to calculate the measurement outcome. Therefore it was difficult to directly compare the findings. Nevertheless an attempt was made to summarise the key findings of the papers.

Step counts are the most frequently reported outcome measure of physical activity in individuals with neurological disorders, and the evidence suggests that ankle-worn biaxial or triaxial accelerometer-type devices provide the most accurate measurement. There is conflicting evidence regarding the validity and reliability of wearable activity monitors in measuring activity counts, while accelerometer-type devices appear to be more appropriate in estimating energy expenditure than multisensor devices, which are more frequently used. The sections below describe these findings in greater detail.

\section{Ankle-Worn Devices Provide the Most Accurate Measurement of Step Counts}

Step counts are the most frequently reported outcome measure of physical activity in individuals with neurological disorders. The evidence suggests that for accurate and reliable measurements of step counts, a number of factors need to be considered. Firstly the validity and reliability of wearable activity monitors in measuring step counts appears to be dependent on the type of device that is used. Spring-mounted lever arm pedometers appear to underestimate step counts in participants with a range of neurological disorders, particularly at slower walking speeds, and are also less accurate for short walking trajectories [27, 32, 42]. Similarly uniaxial accelerometers appear to underestimate steps in slower walking conditions $[38,51]$. Using multiaxial accelerometers appears to be a less speed-dependent method of counting steps, producing more accurate measurements [27, 35, 39, 42, 44,53]. The validity and reliability of wearable activity monitors in measuring step counts also appears to be dependent upon the position on the body in which the device is placed. Activity monitors positioned on the ankle appear to be more accurate than wrist-mounted and waist-mounted devices in counting steps, particularly during slow walking conditions $[39,42,43]$. This may be because larger accelerations occur at the ankle during walking due to the distance from 


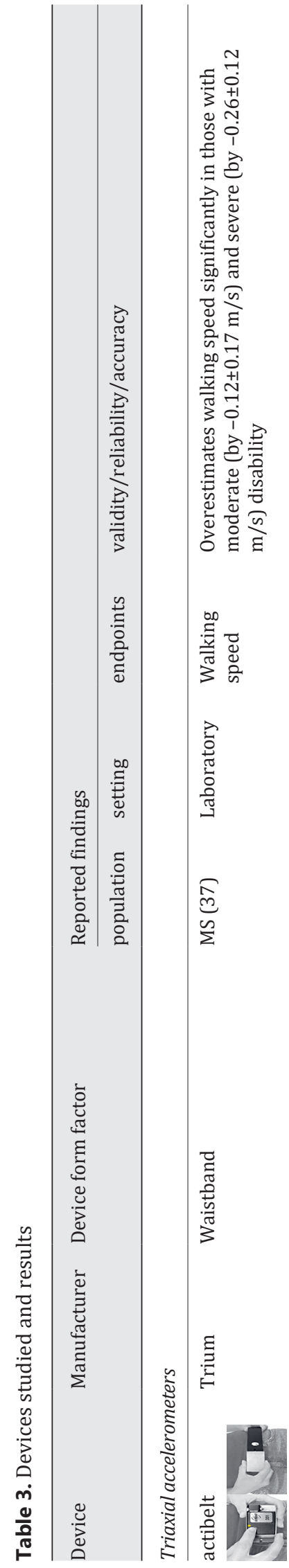

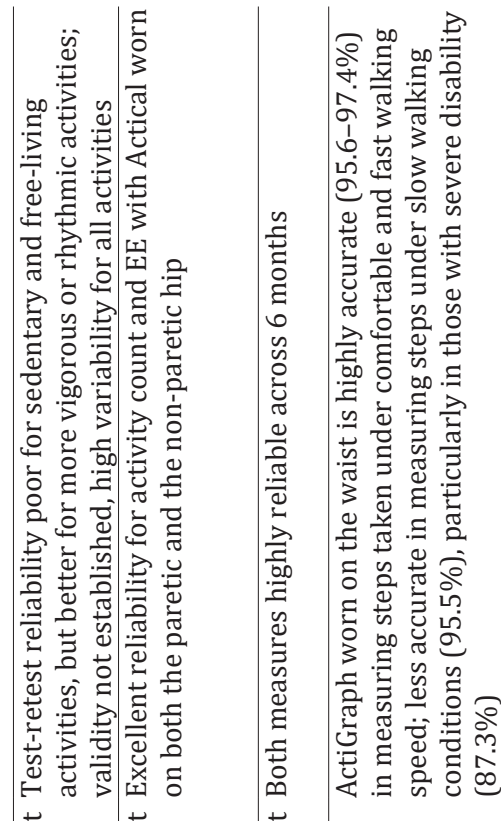
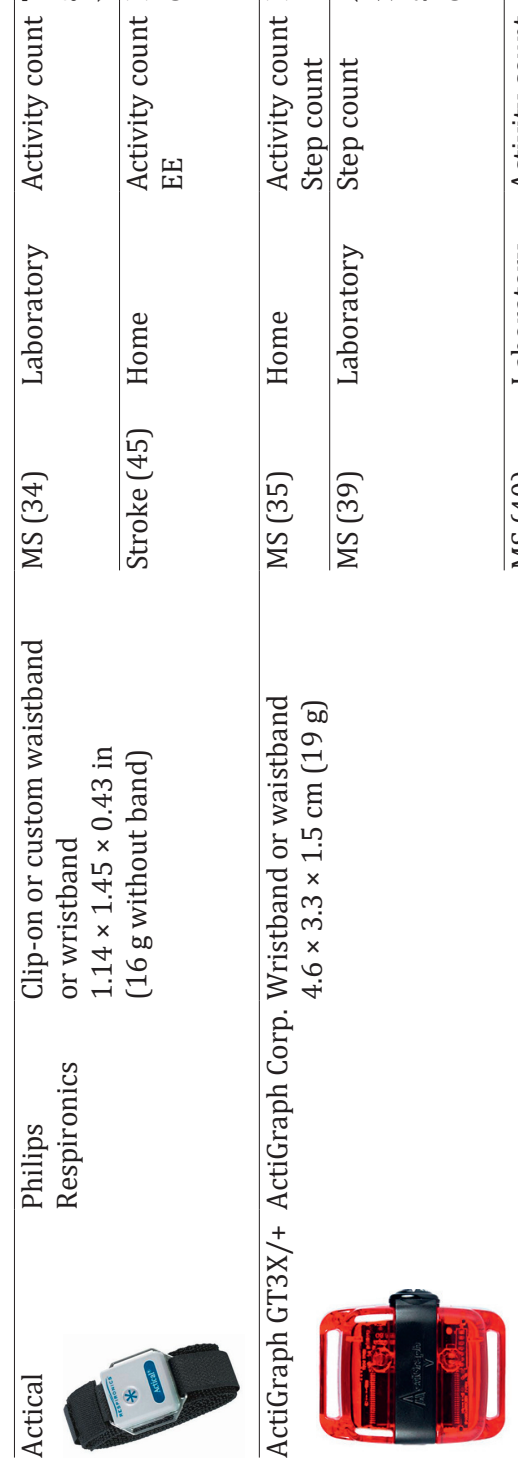
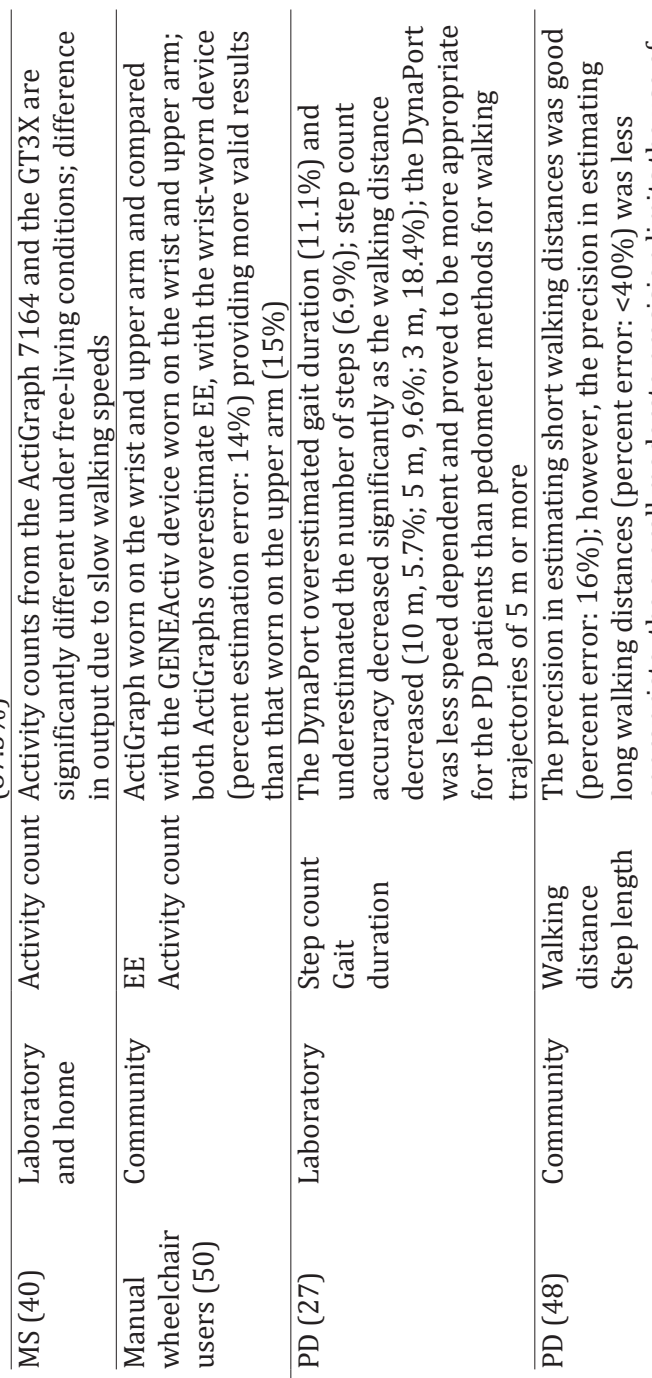
Giggins et al.: Physical Activity Monitoring in Patients with Neurological Disorders: A Review of Novel Body-Worn Devices

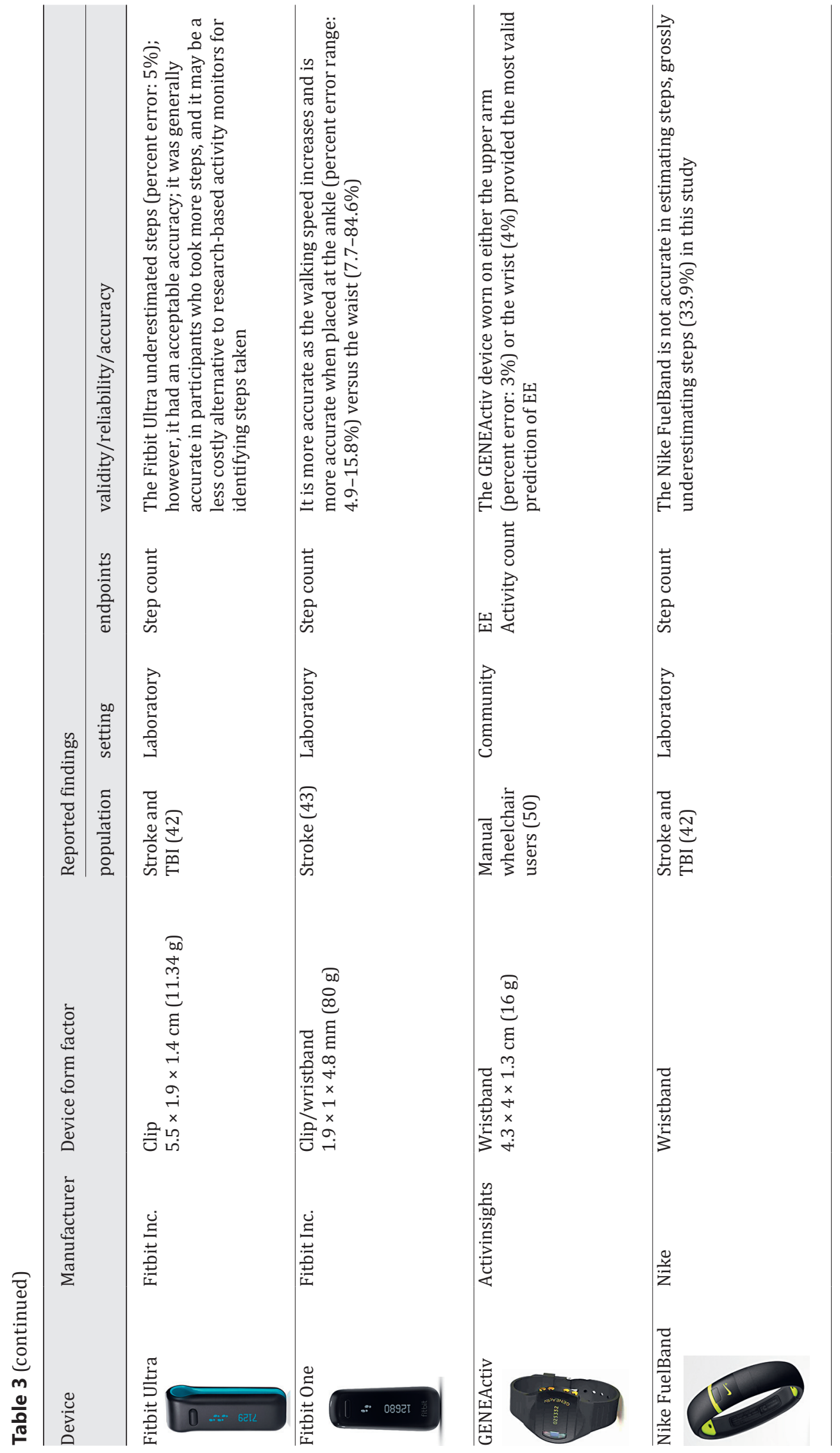


Giggins et al.: Physical Activity Monitoring in Patients with Neurological Disorders: A Review of Novel Body-Worn Devices
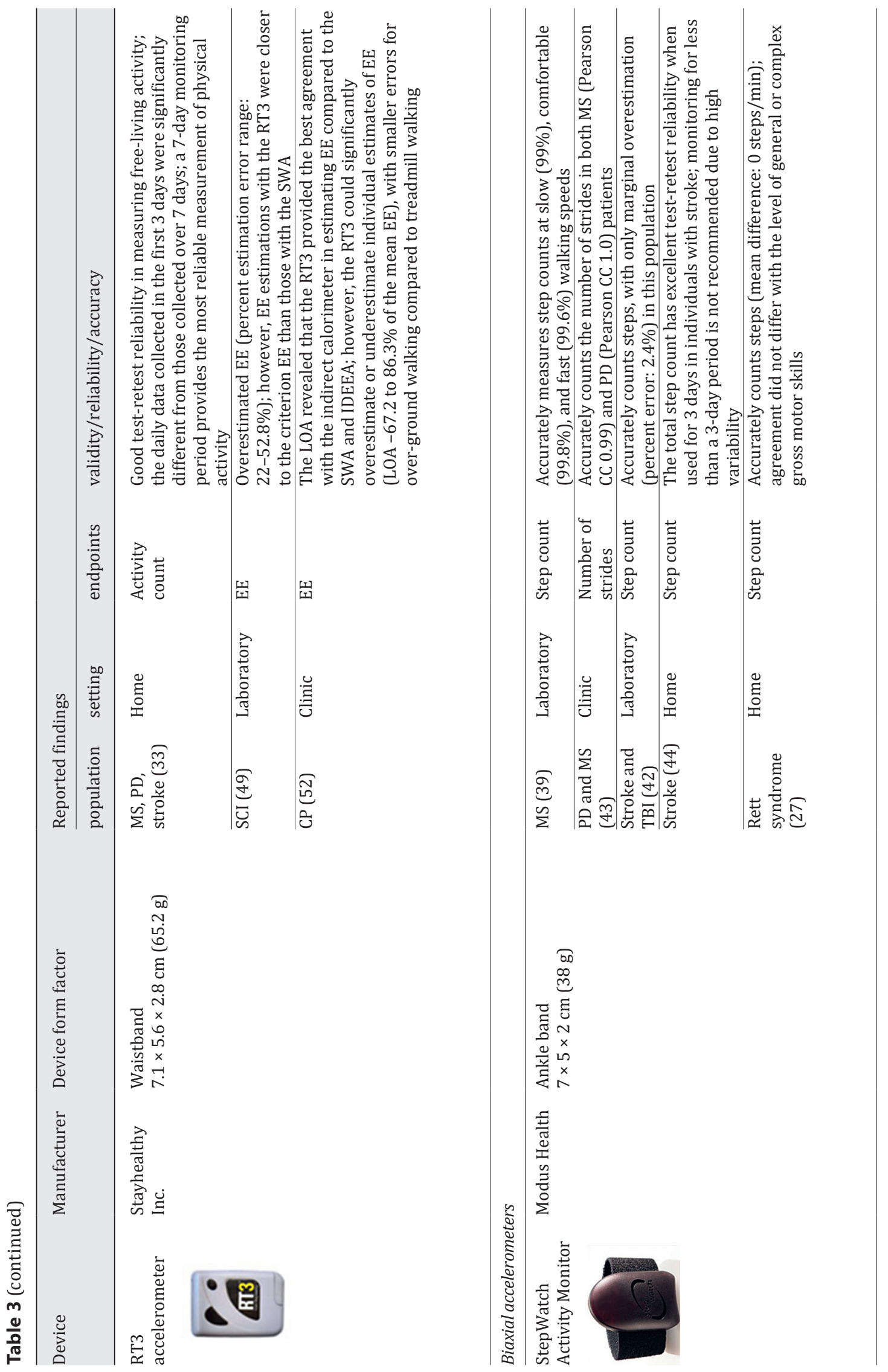


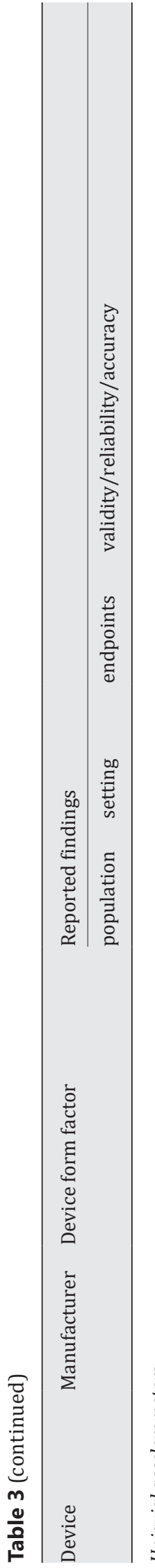

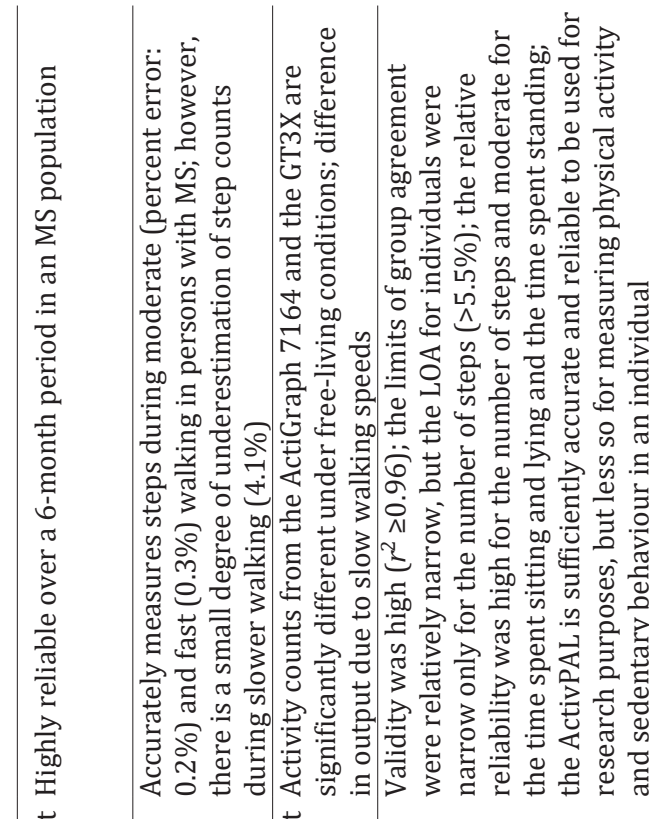

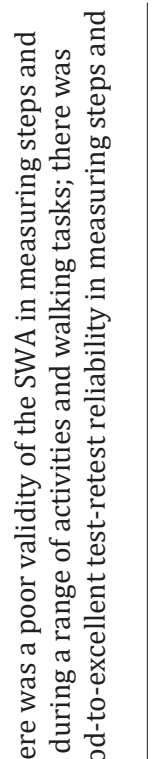
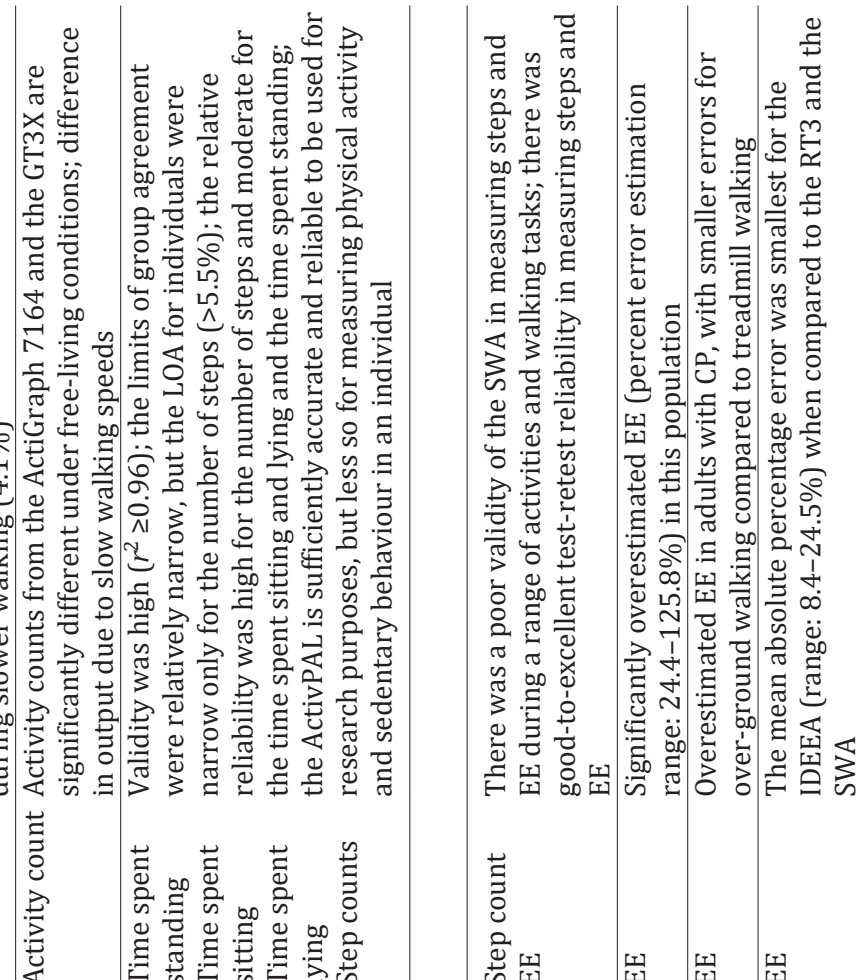

言

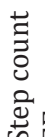
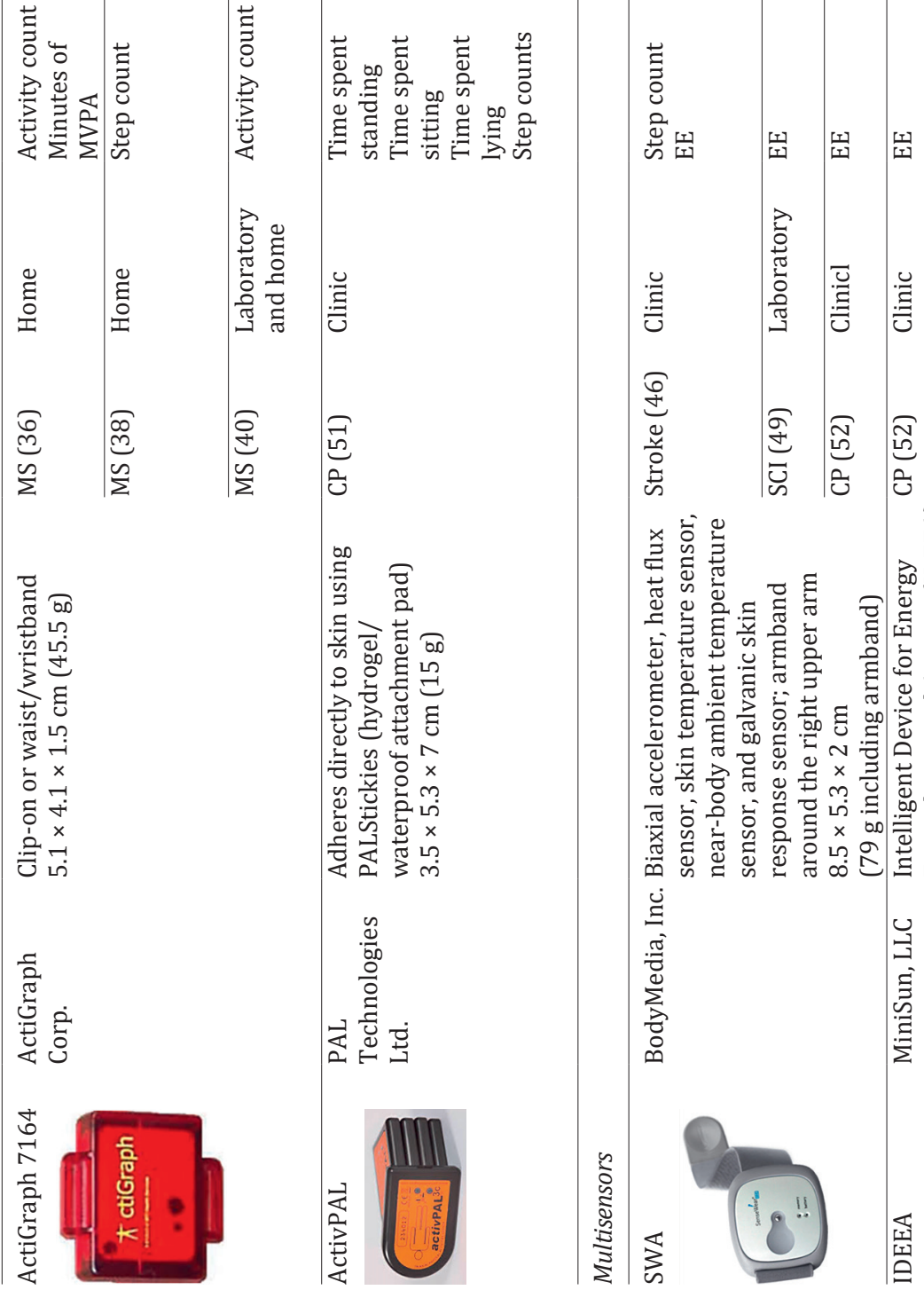

号

里

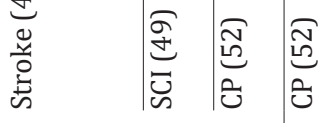

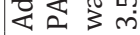

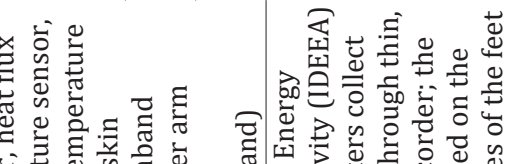

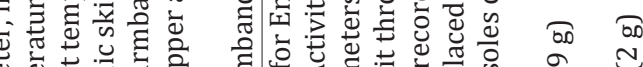

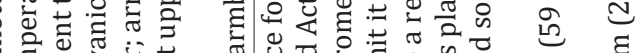

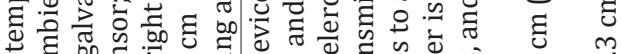

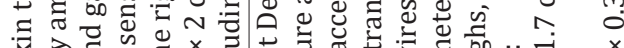
约

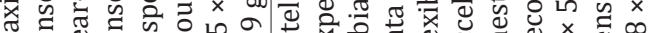

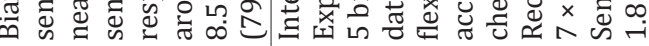


Giggins et al.: Physical Activity Monitoring in Patients with Neurological Disorders: A Review of Novel Body-Worn Devices

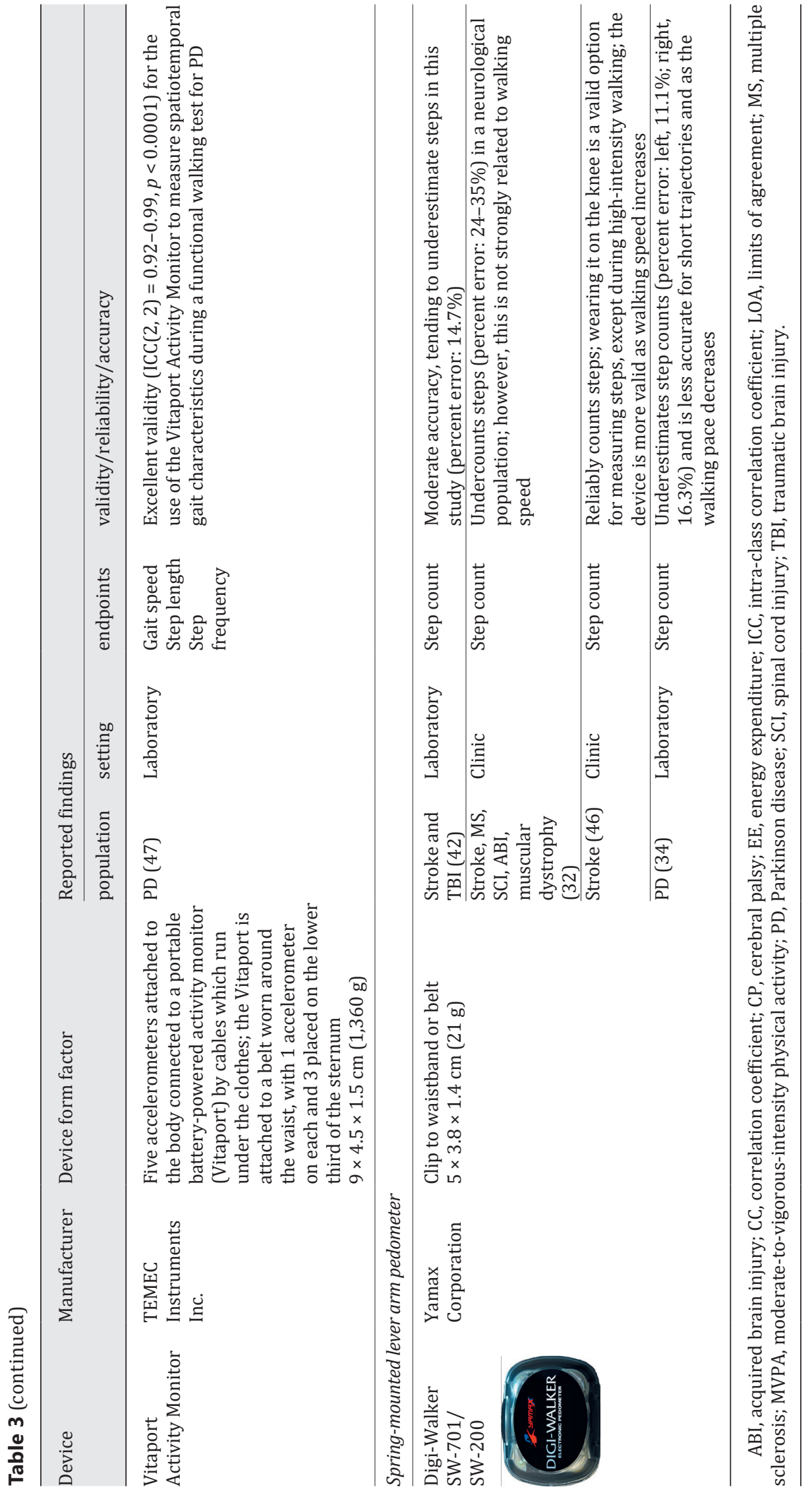


Giggins et al.: Physical Activity Monitoring in Patients with Neurological Disorders: A Review of Novel Body-Worn Devices

the pivot point of the hip. Many device manufacturers recommend that monitoring devices are best positioned at the waist for usability reasons. However, wearing a device around the waist in the centre of the back is considered uncomfortable by many, especially when sitting and driving [33], making long-term adherence in the home environment a challenge to achieve. Therefore, for accurate step count measurements in individuals with neurological disorders, it is recommended, based on the evidence, to use biaxial or triaxial accelerometertype devices, positioning the device around the ankle.

\section{Validity and Reliability of Accelerometer Activity Counts}

A number of studies have reported accelerometer activity counts as a measure of physical activity [33-36, 40, 45, 50]; however, the evidence is conflicting regarding the validity and reliability of this measure in patients with neurological disorders. Some authors report good reliability in measuring activity counts during free-living activities from an activity monitor positioned at the waist $[33,36,45]$. However, others found that an accelerometer positioned around the waist was not reliable at measuring activity counts during sedentary and freeliving activities [34]. Two studies reported on the validity of activity count outputs from accelerometers, and conflicting findings were also reported $[34,50]$.

\section{Multisensor Devices Are Inaccurate in Estimating Energy Expenditure}

Four studies included in this review reported on the accuracy of using a wearable device in estimating energy expenditure in this population. Multisensor devices such as the SWA are most frequently used to estimate energy expenditure, but this device was shown to be inaccurate in estimating energy expenditure in this population $[27,49,52]$. Similarly, the multisensor Intelligent Device for Energy Expenditure and Activity (IDEEA) was shown to be inaccurate in estimating energy expenditure [52]. Accelerometer devices may be more appropriate for estimating energy expenditure. The Actical triaxial accelerometer was shown to have excellent day-to-day reliability in estimating energy expenditure during free-living physical activities in individuals with stroke living in the community [45].

\section{Limitations}

There are a number of limitations to this review that need to be considered. The majority of the studies identified in this review include a small sample of participants. In addition the majority of the studies were conducted in a controlled laboratory or clinical setting, and much more work is required to establish the accuracy of measurements in free-living environments. Despite the best efforts of the authors, it is possible that some studies were not identified in the literature search, or were excluded given the study selection criteria and the electronic databases that were searched to retrieve studies. However, given the systematic approach that was adopted, this review can be accepted as an accurate reflection of the existing evidence exploring activity monitoring in individuals with neurological disorders. Nonetheless this is a rapidly expanding and evolving field of research; therefore the findings of this review should be substantiated as new evidence emerges and new studies are published.

\section{Recommendations for Clinical Use}

Activity monitors selected for clinical use should be confined to those for which there is a body of evidence outlining the validity and the reliability of the measurements produced. In addition the psychometric properties of the monitor selected should be established in the clinical cohort of interest, as the validity and reliability of a monitor in one cohort does not 
Giggins et al.: Physical Activity Monitoring in Patients with Neurological Disorders: A Review of Novel Body-Worn Devices

necessarily infer the same in another. Furthermore consideration should be given to the stage and severity of a disorder to ensure the monitor selection is appropriate.

Besides the validity and the reliability of the measurements produced, other factors need to be considered when selecting a device. One should also consider the cost of obtaining the device (hardware and software) and its attachments (e.g., belts or adhesives). Other factors which also warrant attention include the aesthetic appearance of the device, the comfort and wearability of the device, the user experience, the obtrusiveness of the device, the device's durability, and the privacy and discretion afforded with its use. Taking these human factors into consideration when selecting a device will help minimise the impact of potential user acceptance issues that may arise.

Further work is required in this field before wearable activity monitoring can be more widely implemented. Standardised activity monitoring protocols need to be developed for implementing these devices in clinical trials and clinical practice, and consensus is required as to the reporting and interpretation of derived variables.

\section{Conclusions}

Recent technological advances have led to the development of a wide range of devices capable of measuring physical activity and mobility. Wearable sensors have immense potential in clinical trials and clinical practice; however, as yet they have not been widely adopted. This review of the literature attempted to summarise the evidence exploring the validity and reliability of body-worn monitors that measure physical activity and mobility in patients with neurological disorders. The variety of methods used in the included studies limits the ability to draw definitive conclusions. Nonetheless, the evidence appears to suggest that multiaxial accelerometer devices - in particular the StepWatch activity monitor and the ActiGraph GT3X - positioned around the ankle most accurately measure step counts in patients with neurological disorders, and are acceptable in slow walking conditions. The findings regarding the reliability and validity of activity counts and energy expenditure are largely inconclusive in this population.

\section{Appendix 1}

\section{Search Terms}

Free-text and MeSH terms used in the PubMed database:

accelerometry [MeSH] OR accelerometer OR accelerometer and gyroscope OR pedometer OR physical activity trackers OR activity trackers OR activity monitor OR activity tracker OR fitness tracker OR physical activity tracker OR physical activity monitor OR step counter OR wearable technology OR wearable sensor OR wearable device OR wearable OR sensor OR inertial sensor OR inertial measurement unit OR IMU

AND

physical fitness [MeSH] OR motion [MeSH] OR energy metabolism [MeSH] OR motor activity $[\mathrm{MeSH}]$ OR steps

AND

validity $\mathrm{OR}$ validation $\mathrm{OR}$ validation study $\mathrm{OR}$ reliability $\mathrm{OR}$ reliability study OR accuracy OR comparison OR comparison study 
Giggins et al.: Physical Activity Monitoring in Patients with Neurological Disorders: A Review of Novel Body-Worn Devices

\section{Appendix 2}

\section{Quality Assessment of Method Comparison Validation Studies}

The following criteria were used for assessing the methodologic quality of method comparison studies as either "yes," "no," or "unclear":

\begin{tabular}{|c|c|c|c|c|}
\hline & & $\begin{array}{l}\text { Yes } \\
(\checkmark)\end{array}$ & $\begin{array}{l}\text { No } \\
(x)\end{array}$ & $\begin{array}{l}\text { Unable to } \\
\text { Determine } \\
\text { (?) }\end{array}$ \\
\hline & & $(1)$ & $(0)$ & $(0)$ \\
\hline 1 & $\begin{array}{l}\text { Was the spectrum of participants representative of patients who } \\
\text { will receive the test in practice? }\end{array}$ & & & \\
\hline 2 & Were selection criteria clearly described? & & & \\
\hline 3 & $\begin{array}{l}\text { Is the reference measurement an acceptable measure of physical } \\
\text { activity of the patient? }\end{array}$ & & & \\
\hline 4 & $\begin{array}{l}\text { Is the index test device and reference standard device } \\
\text { measurement collected on the same patient at the same time } \\
\text { (i.e., both measurements are carried out concurrently)? }\end{array}$ & & & \\
\hline 5 & $\begin{array}{l}\text { Did all of the patients receive the same reference device } \\
\text { measurement? }\end{array}$ & & & \\
\hline 6 & $\begin{array}{l}\text { Were the index test and reference standard device measurements } \\
\text { performed independently (blind) of each other? }\end{array}$ & & & \\
\hline 7 & $\begin{array}{l}\text { Were the same clinical data available when index test results were } \\
\text { interpreted as would be available when the tests are used in practice? }\end{array}$ & & & \\
\hline 8 & $\begin{array}{l}\text { Was the execution of the index test described in sufficient detail to } \\
\text { permit replication of the test? }\end{array}$ & & & \\
\hline 9 & $\begin{array}{l}\text { Was the execution of the reference standard described in sufficient } \\
\text { detail to permit its replication? }\end{array}$ & & & \\
\hline 10 & $\begin{array}{l}\text { Was the study free of commercial funding from the manufacturers of } \\
\text { the device(s) being validated in the study (i.e., is there any indication } \\
\text { in the article that funding was received)? }\end{array}$ & & & \\
\hline
\end{tabular}

\begin{tabular}{|c|c|c|c|c|c|c|c|c|c|c|}
\hline Study & 1 & 2 & 3 & 4 & 5 & 6 & 7 & 8 & 9 & 10 \\
\hline Bania [51] & $\checkmark$ & $\checkmark$ & $\checkmark$ & $x$ & $\checkmark$ & $\checkmark$ & $\checkmark$ & $x$ & $\checkmark$ & $\checkmark$ \\
\hline Dijkstra et al. [27] & $\checkmark$ & $\checkmark$ & $\checkmark$ & $x$ & $\checkmark$ & $?$ & $\checkmark$ & $\checkmark$ & $\checkmark$ & $\checkmark$ \\
\hline Downs et al. [53] & $\checkmark$ & $\checkmark$ & $\checkmark$ & $x$ & $\checkmark$ & $?$ & $\checkmark$ & $\checkmark$ & $\checkmark$ & $\checkmark$ \\
\hline Elsworth et al. [32] & $\checkmark$ & $\checkmark$ & $\checkmark$ & $\checkmark$ & $\checkmark$ & $?$ & $\checkmark$ & $\checkmark$ & $\checkmark$ & $\checkmark$ \\
\hline Fulk et al. [42] & $\checkmark$ & $\checkmark$ & $\checkmark$ & $\checkmark$ & $\checkmark$ & $?$ & $\checkmark$ & $\checkmark$ & $\checkmark$ & $\checkmark$ \\
\hline Hiremath and Ding [49] & $\checkmark$ & $\checkmark$ & $\checkmark$ & $\checkmark$ & $x$ & $\checkmark$ & $\checkmark$ & $\checkmark$ & $\checkmark$ & $\checkmark$ \\
\hline Kayes et al. [34] & $\checkmark$ & $\checkmark$ & $\checkmark$ & $\checkmark$ & $\checkmark$ & $?$ & $\checkmark$ & $\checkmark$ & $\checkmark$ & $\checkmark$ \\
\hline Klassen et al. [43] & $\checkmark$ & $\checkmark$ & $\checkmark$ & $x$ & $\checkmark$ & $?$ & $\checkmark$ & $\checkmark$ & $\checkmark$ & $\checkmark$ \\
\hline Lord et al. [47] & $\checkmark$ & $\checkmark$ & $\checkmark$ & $\checkmark$ & $\checkmark$ & $?$ & $\checkmark$ & $\checkmark$ & $\checkmark$ & $\checkmark$ \\
\hline Motl et al. [37] & $\checkmark$ & $\checkmark$ & $\checkmark$ & $\checkmark$ & $\checkmark$ & $\checkmark$ & $\checkmark$ & $\checkmark$ & $\checkmark$ & $x$ \\
\hline Motl et al. [38] & $\checkmark$ & $\checkmark$ & $\checkmark$ & $\checkmark$ & $\checkmark$ & $?$ & $\checkmark$ & $\checkmark$ & $\checkmark$ & $\checkmark$ \\
\hline Nightingale et al. [50] & $\checkmark$ & $x$ & $\checkmark$ & $\checkmark$ & $\checkmark$ & $?$ & $\checkmark$ & $\checkmark$ & $\checkmark$ & $\checkmark$ \\
\hline Ryan et al. [52] & $\checkmark$ & $\checkmark$ & $\checkmark$ & $\checkmark$ & $\checkmark$ & $?$ & $\checkmark$ & $\checkmark$ & $\checkmark$ & $\checkmark$ \\
\hline Sandroff et al. [39] & $\checkmark$ & $\checkmark$ & $\checkmark$ & $\checkmark$ & $\checkmark$ & $?$ & $\checkmark$ & $\checkmark$ & $\checkmark$ & $\checkmark$ \\
\hline Schmidt et al. [41] & $\checkmark$ & $\checkmark$ & $\checkmark$ & $\checkmark$ & $\checkmark$ & $x$ & $\checkmark$ & $\checkmark$ & $\checkmark$ & $\checkmark$ \\
\hline Speelman et al. [48] & $\checkmark$ & $x$ & $\checkmark$ & $?$ & $\checkmark$ & $?$ & $\checkmark$ & $\checkmark$ & $\checkmark$ & $\checkmark$ \\
\hline Vanroy et al. [46] & $\checkmark$ & $\checkmark$ & $\checkmark$ & $\checkmark$ & $\checkmark$ & $?$ & $\checkmark$ & $\checkmark$ & $\checkmark$ & $\checkmark$ \\
\hline
\end{tabular}




\section{Ethics Statement}

The authors have no ethical conflicts to disclose.

\section{Conflict of Interest Statement}

I.C. and L.W. work for Novartis. O.M.G. is on secondment with Novartis.

\section{Funding Sources}

This publication has emanated from research conducted with the financial support of Science Foundation Ireland (SFI) under Grant No. 15/IFA/3009.

\section{References}

1 Thompson P, Buchner D, Pina IL, Balady GJ, Williams MA, Marcus BH, et al; American Heart Association Council on Clinical Cardiology Subcommittee on Exercise, Rehabilitation, and Prevention; American Heart Association Council on Nutrition, Physical Activity, and Metabolism Subcommittee on Physical Activity: Exercise and physical activity in the prevention and treatment of atherosclerotic cardiovascular disease: a statement from the Council on Clinical Cardiology (Subcommittee on Exercise, Rehabilitation, and Prevention) and the Council on Nutrition, Physical Activity, and Metabolism (Subcommittee on Physical Activity). Circulation 2003;107: 3109-3116.

-2 Hu G, Lakka TA, Kilpeläinen TO, Tuomilehto J: Epidemiological studies of exercise in diabetes prevention. Appl Physiol Nutr Metab 2007;32:583-595.

-3 Lee IM: Physical activity and cancer prevention - data from epidemiologic studies. Med Sci Sports Exerc 2003; 35:1823-1827.

4 Howe TE, Shea B, Dawson LJ, Downie F, Murray A, Ross C, et al: Exercise for preventing and treating osteoporosis in postmenopausal women. Cochrane Database Syst Rev 2011;7:CD000333.

5 Poirier P, Després JP: Exercise in weight management of obesity. Cardiol Clin 2001;19:459-470.

6 Hernández-Molina G, Reichenbach S, Zhang B, Lavalley M, Felson DT: Effect of therapeutic exercise for hip osteoarthritis pain: results of a meta-analysis. Arthritis Rheum 2008;59:1221-1228.

7 Jacobs PL, Nash MS: Exercise recommendations for individuals with spinal cord injury. Sports Med 2004;34: 727-751.

8 Caspersen CJ, Powell KE, Christenson GM: Physical activity, exercise, and physical fitness: definitions and distinctions for health-related research. Public Health Rep 1985;100:126-131.

-9 Hirvensalo M, Rantanen T, Heikkinen E: Mobility difficulties and physical activity as predictors of mortality and loss of independence in the community-living older population. J Am Geriatr Soc 2000;48:493-498.

10 Bo M, Fonte G, Pivaro F, Bonetto M, Comi C, Giorgis V, et al: Prevalence of and factors associated with prolonged length of stay in older hospitalized medical patients. Geriatr Gerontol Int 2016;16:314-321.

11 Miller EA, Weissert WG: Predicting elderly people's risk for nursing home placement, hospitalization, functional impairment, and mortality: a synthesis. Med Care Res Rev 2000;57:259-297.

12 Bandmann E: Physical activity questionnaires: a critical review of methods used in validity and reproducibility studies; thesis, Stockholm, 2008.

13 Jørstad-Stein E, Hauer K, Becker C, Bonnefoy M, Nakash R, Skelton D, et al: Suitability of physical activity questionnaires for older adults in fall-prevention trials: a systematic review. J Aging Phys Act 2005;13:461-481.

14 Van Remoortel H, Giavedoni S, Raste Y, Burtin C, Louvaris Z, Gimeno-Santos E, et al: Validity of activity monitors in health and chronic disease: a systematic review. Int J Behav Nutr Phys Act 2012;9:84.

15 Patel S, Park H, Bonato P, Chan L, Rodgers M: A review of wearable sensors and systems with application in rehabilitation. J Neuroeng Rehabil 2012;9:21.

16 Robles-García V, Corral-Bergantiños Y, Espinosa N, Jácome MA, García-Sancho C, Cudeiro J, et al: Spatiotemporal gait patterns during overt and covert evaluation in patients with Parkinson's disease and healthy subjects: is there a Hawthorne effect? J Appl Biomech 2015;31:189-194.

17 Byrom B, Rowe DA: Measuring free-living physical activity in COPD patients: deriving methodology standards for clinical trials through a review of research studies. Contemp Clin Trials 2016;47:172-184.

18 Dhillon SS, Sima CA, Kirkham AR, Syed N, Camp PG: Physical activity measurement accuracy in individuals with chronic lung disease: a systematic review with meta-analysis of method comparison studies. Arch Phys Med Rehabil 2015;96:2079-2088.e10. 


\begin{tabular}{|c|c|}
\hline Digit Biomark 2017;1:14-42 & \\
\hline DOI: $10.1159 / 000477384$ & $\begin{array}{l}\text { (c) } 2017 \text { The Author(s). Published by S. Karger AG, Basel } \\
\text { www.karger.com/dib }\end{array}$ \\
\hline
\end{tabular}

Giggins et al.: Physical Activity Monitoring in Patients with Neurological Disorders: A Review of Novel Body-Worn Devices

19 Gebruers N, Vanroy C, Truijen S, Engelborghs S, De Deyn PP: Monitoring of physical activity after stroke: a systematic review of accelerometry-based measures. Arch Phys Med Rehabil 2010;91:288-297.

20 Block VAJ, Pitsch E, Tahir P, Cree BAC, Allen DD, Gelfand JM: Remote physical activity monitoring in neurological disease: a systematic review. PLoS One 2016;11:e0154335.

21 Godinho C, Domingos J, Cunha G, Santos AT, Fernandes RM, Abreu D, et al: A systematic review of the characteristics and validity of monitoring technologies to assess Parkinson's disease. J Neuroeng Rehabil 2016;13: 24.

22 Gehlsen G, Beekman K, Assmann N, Winant D, Seidle M, Carter A: Gait characteristics in multiple sclerosis: progressive changes and effects of exercise on parameters. Arch Phys Med Rehabil 1986;67:536-539.

23 Moreno Catalá M, Woitalla D, Arampatzis A: Central factors explain muscle weakness in young fallers with Parkinson's disease. Neurorehabil Neural Repair 2013;27:753-759.

24 Thibaut A, Chatelle C, Ziegler E, Bruno MA, Laureys S, Gosseries O: Spasticity after stroke: physiology, assessment and treatment. Brain Inj 2013;27:1093-1105.

25 Jankovic J: Parkinson's disease: clinical features and diagnosis. J Neurol Neurosurg Psychiatry 2008;79:368376.

26 Zijlstra W, Hof AL: Assessment of spatio-temporal gait parameters from trunk accelerations during human walking. Gait Posture 2003;18:1-10.

27 Dijkstra B, Zijlstra W, Scherder E, Kamsma Y: Detection of walking periods and number of steps in older adults and patients with Parkinson's disease: accuracy of a pedometer and an accelerometry-based method. Age Ageing 2008;37:436-441.

28 Moher D, Liberati A, Tetzlaff J, Altman DG, Grp P: Preferred reporting items for systematic reviews and metaanalyses: the PRISMA statement [reprinted from Ann Intern Med]. Phys Ther 2009;89:873-880.

29 Taraldsen K, Chastin SFM, Riphagen II, Vereijken B, Helbostad JL: Physical activity monitoring by use of accelerometer-based body-worn sensors in older adults: a systematic literature review of current knowledge and applications. Maturitas 2012;71:13-19.

30 Koo TK, Li MY: A guideline of selecting and reporting intraclass correlation coefficients for reliability research. J Chiropr Med 2016;15:155-163.

-31 Whiting P, Rutjes AWS, Reitsma JB, Bossuyt PMM, Kleijnen J: The development of QUADAS: a tool for the quality assessment of studies of diagnostic accuracy included in systematic reviews. BMC Med Res Methodol 2003;3:25.

-32 Elsworth C, Dawes H, Winward C, Howells K, Collett J, Dennis A, et al: Pedometer step counts in individuals with neurological conditions. Clin Rehabil 2009;23:171-175.

-33 Hale LA, Pal J, Becker I: Measuring free-living physical activity in adults with and without neurologic dysfunction with a triaxial accelerometer. Arch Phys Med Rehabil 2008;89:1765-1771.

-34 Kayes NM, Schluter PJ, McPherson KM, Leete M, Mawston G, Taylor D: Exploring Actical accelerometers as an objective measure of physical activity in people with multiple sclerosis. Arch Phys Med Rehabil 2009;90:594601.

-35 Learmonth YC, Dlugonski DD, Pilutti LA, Sandroff BM, Motl RW: The reliability, precision and clinically meaningful change of walking assessments in multiple sclerosis. Mult Scler 2013;19:1784-1791.

-36 Motl RW, McAuley E, Klaren R: Reliability of physical-activity measures over six months in adults with multiple sclerosis: implications for designing behavioral interventions. Behav Med 2014;40:29-33.

37 Motl RW, Weikert M, Suh Y, Sosnoff JJ, Pula J, Soaz C, et al: Accuracy of the actibelt ${ }^{\circledR}$ accelerometer for measuring walking speed in a controlled environment among persons with multiple sclerosis. Gait Posture 2012;35: 192-196.

-38 Motl RW, Snook EM, Agiovlasitis S: Does an accelerometer accurately measure steps taken under controlled conditions in adults with mild multiple sclerosis? Disabil Health J 2011;4:52-57.

-39 Sandroff BM, Motl RW, Pilutti LA, Learmonth YC, Ensari I, Dlugonski D, et al: Accuracy of StepWatch ${ }^{\mathrm{TM}}$ and ActiGraph $^{\mathrm{TM}}$ accelerometers for measuring steps taken among persons with multiple sclerosis. PLoS One 2014;9:e93511.

40 Sandroff BM, Motl RW: Comparison of ActiGraph activity monitors in persons with multiple sclerosis and controls. Disabil Rehabil 2013;35:725-731.

41 Schmidt AL, Pennypacker ML, Thrush AH, Leiper CI, Craik RL: Validity of the StepWatch Step Activity Monitor: preliminary findings for use in persons with Parkinson disease and multiple sclerosis. J Geriatr Phys Ther 2011;34:41-45.

-42 Fulk GD, Combs SA, Danks KA, Nirider CD, Raja B, Reisman DS: Accuracy of 2 activity monitors in detecting steps in people with stroke and traumatic brain injury. Phys Ther 2014;94:222-229.

43 Klassen TD, Simpson LA, Lim SB, Louie DR, Parappilly B, Sakakibara BM, et al: "Stepping up" activity poststroke: ankle-positioned accelerometer can accurately record steps during slow walking. Phys Ther 2016;96: 355-360.

44 Mudge S, Stott NS: Test-retest reliability of the StepWatch Activity Monitor outputs in individuals with chronic stroke. Clin Rehabil 2008;22:871-877.

45 Rand D, Eng J, Tang P, Jeng J, Hung C: How active are people with stroke? Use of accelerometers to assess physical activity. Stroke 2009;40:163-168. 
46 Vanroy C, Vissers D, Cras P, Beyne S, Feys H, Vanlandewijck Y, et al: Physical activity monitoring in stroke: SenseWear Pro2 Activity accelerometer versus Yamax Digi-Walker SW-200 pedometer. Disabil Rehabil 2014; 36:1695-1703.

47 Lord S, Rochester L, Baker K, Nieuwboer A: Concurrent validity of accelerometry to measure gait in Parkinsons disease. Gait Posture 2008;27:357-359.

-48 Speelman AD, van Nimwegen M, Borm GF, Bloem BR, Munneke M: Monitoring of walking in Parkinson's disease: validation of an ambulatory activity monitor. Parkinsonism Relat Disord 2011;17:402-404.

49 Hiremath SV, Ding D: Evaluation of activity monitors in manual wheelchair users with paraplegia. J Spinal Cord Med 2011;34:110-117.

50 Nightingale TE, Walhin JP, Thompson D, Bilzon JL: Influence of accelerometer type and placement on physical activity energy expenditure prediction in manual wheelchair users. PLoS One 2015;10:e0126086.

51 Bania T: Measuring physical activity in young people with cerebral palsy: validity and reliability of the ActivPAL $^{\mathrm{TM}}$ monitor. Physiother Res Int 2014;19:186-192.

52 Ryan JM, Walsh M, Gormley J: A comparison of three accelerometry-based devices for estimating energy expenditure in adults and children with cerebral palsy. J Neuroeng Rehabil 2014;11:116.

53 Downs J, Leonard H, Hill K: Initial assessment of the StepWatch Activity Monitor ${ }^{\mathrm{TM}}$ to measure walking activity in Rett syndrome. Disabil Rehabil 2012;34:1010-1015. 